\title{
LGBTQ PARENTS' EXPERIENCES WITH EARLY YEARS ENVIRONMENTS
}

by

Michael Butac, BA, University of Guelph, 2012

\author{
An MRP \\ presented to Ryerson University \\ in partial fulfillment of the \\ requirements for the degree of \\ Master of Arts \\ in the Program of \\ Early Childhood Studies
}

Toronto, Ontario, Canada, 2016

(C) Michael Butac 2016 


\section{AUTHOR'S DECLARATION FOR ELECTRONIC SUBMISSION OF A MRP}

I hereby declare that I am the sole author of this MRP. This is a true copy of the MRP, including any required final revisions.

I authorize Ryerson University to lend this MRP to other institutions or individuals for the purpose of scholarly research.

I further authorize Ryerson University to reproduce this MRP by photocopying or by other means, in total or in part, at the request of other institutions or individuals for the purpose of scholarly research.

I understand that my MRP may be made electronically available to the public. 


\section{ABSTRACT \\ LGBTQ Parents' Experiences with Early Years Environments \\ Master of Arts, 2016 \\ Michael Butac \\ Program of Early Childhood Studies, Ryerson University}

This phenomenological study explores LGBTQ parents' experiences in seeking and in being part of early years environments, such as family support programs and childcare services, in Toronto, Ontario. Literature has shown that heteronormativity plays a significant role in early years environments, thereby, silencing other sexualities. This silencing of sexual minorities adds an additional layer to the process of seeking an early years environment, which involves assessing LGBTQ inclusion of such environments. Semi-structured telephone interviews were conducted with LGBTQ parents to compare their experiences to the literature, and to consider implications for future practice and policy. The sample was found to have generally positive experiences. Collaboration was an important factor in creating more positive experiences for parents. Future research should consider further inclusion of bisexual, transgender, and queer individuals in order to continue to better understand their experiences in early years environments and build upon the knowledge gained here.

Keywords: LGBTQ parents, early years environments, family support programs, childcare 


\section{Acknowledgements}

Firstly, I would like to thank all the parents who participated in my study. I cannot thank you enough for the time you dedicated to the research. I would also like to thank the sites that advertised my study. Special thanks to Sharn and Joanne at The 519's Family Resource Centre for welcoming me with open arms, and for being so encouraging and supportive.

Thank you to my supervisor, Dr. Rachel Berman. Thank you for your amazing support throughout this process, and for the time you dedicated to this project. Your dedication to the early childhood field and to your students is a true inspiration. I have learned so much from you.

Thank you to my initial program advisor and second reader, Dr. Marni Binder. Thank you for all the advice you have given me throughout the program and for dedicating your time to me and this project.

I would also like to thank all the other faculty members who believed in me throughout my time in the program, and for telling me to believe in myself. Thank you for seeing my potential and helping me to grow on this educational journey.

Thank you to my colleagues. I cannot imagine what this experience would have been like without you all. I have felt genuine support from many of you, and it has been greatly appreciated.

Finally, this project is ultimately about love and accepting each other's differences. Without the love and acceptance of the following people, I truly would not be where I am today. Thank you to my family and friends for your continuous support and kind words. Thank you to my mom for always telling me to chase my dreams. Your continuous support and unconditional love means the world to me. I love you. Finally, thank you to my partner, Matthew. Thank you for listening to my rambling and making sure I stay on top of my work! Thank you for keeping 
me sane. Thank you for supporting me throughout this journey. Thank you for helping me love who I am. I love you.

Oh, and thank you to my two beautiful cats, Kitty and Maggie, for being purrfect destressors. I will now have more time to give you the attention you desire and truly deserve. 


\section{Dedication}

To the LGBTQ community:

May we continue to break down walls for the generations to follow, and to continue to spread love in places we have been told not to.

To my grandma:

You are the reason I do what I do. I cannot thank you enough for everything you have done for me. Thinking about you, always. I love you. 


\section{Table of Contents}

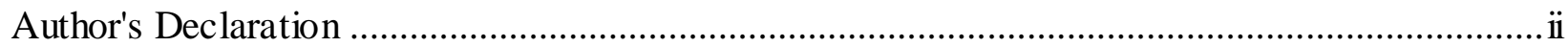

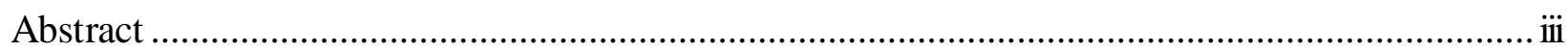

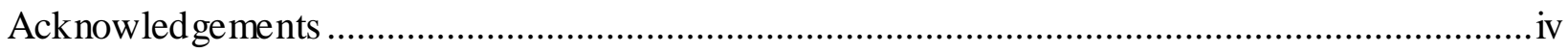

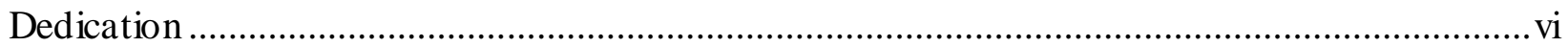

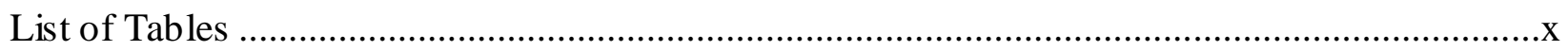

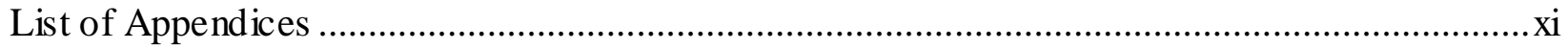

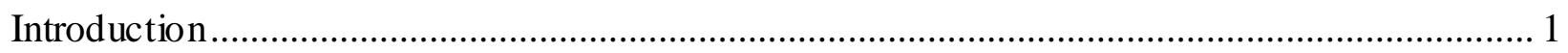

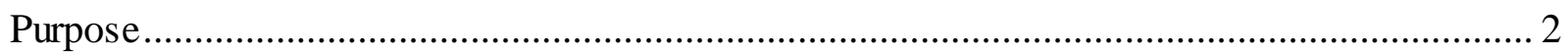

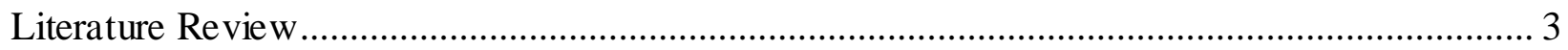

LGBTQ Families in Canada ................................................................................ 3

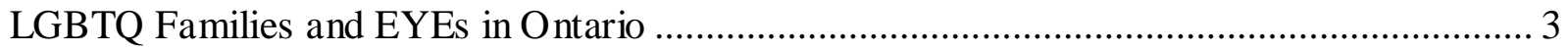

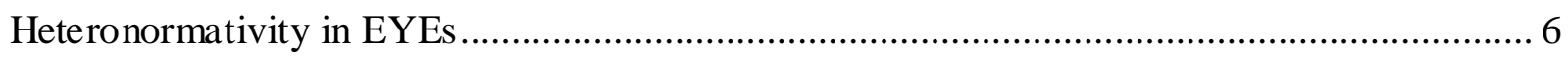

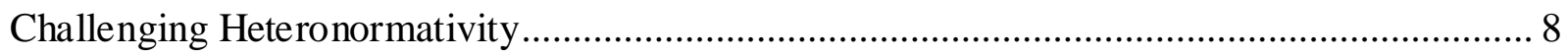

Preschool Selection Considerations .......................................................................... 10

Improving the Experiences of LGBTQ Families in EYEs ............................................ 12

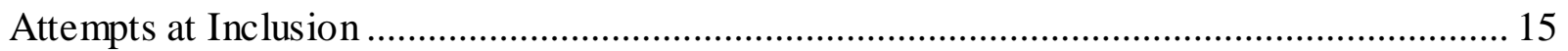

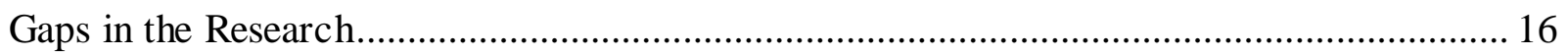

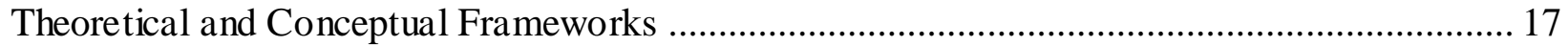

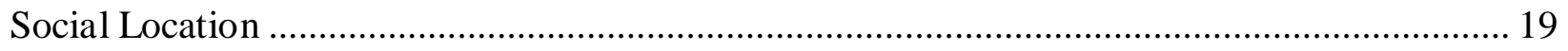

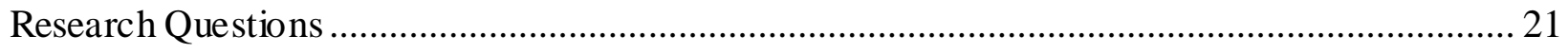




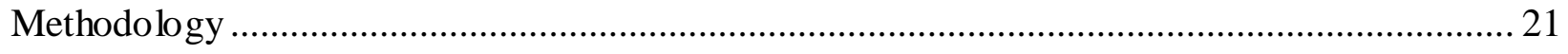

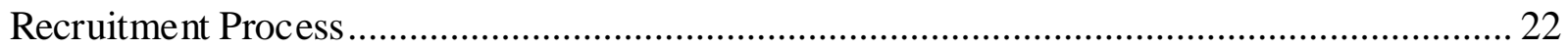

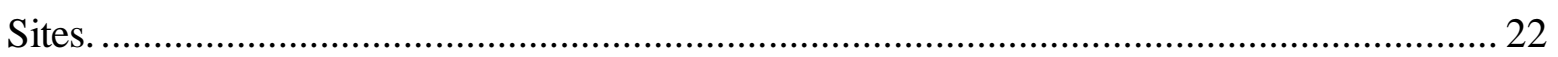

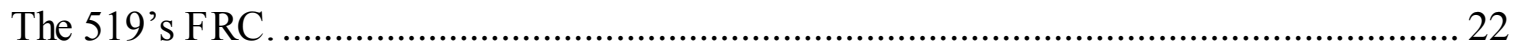

Sherbourne Health Centre's LGBTQPN. ............................................................... 24

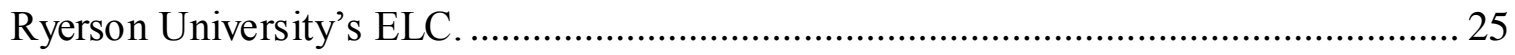

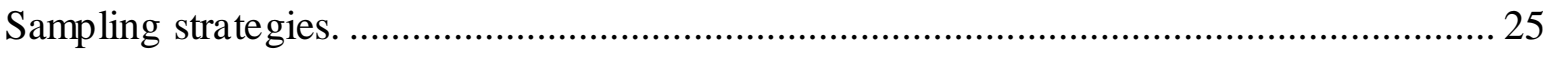

Sample

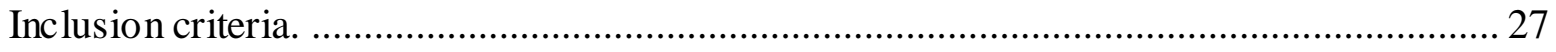

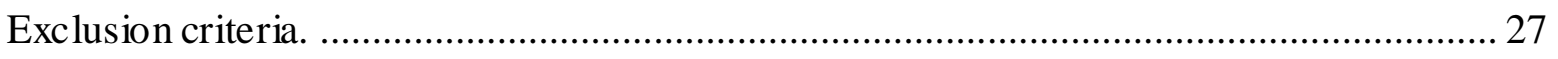

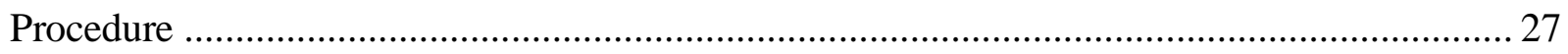

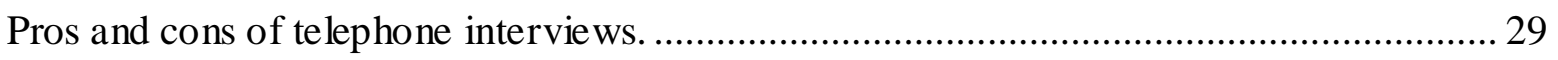

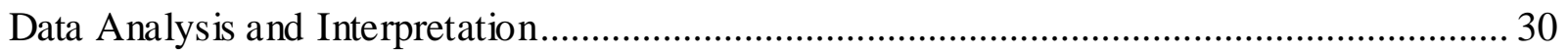

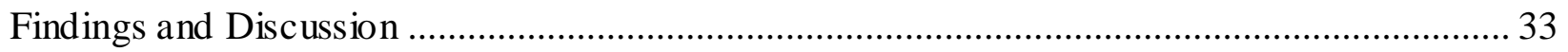

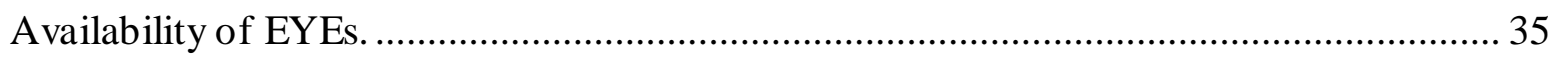

Family support programs versus childcare. ………………................................................. 36

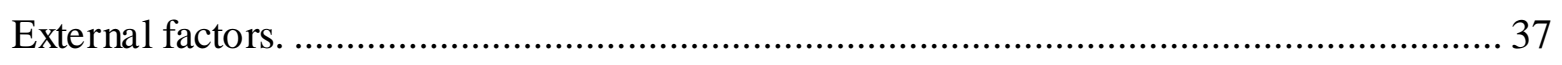

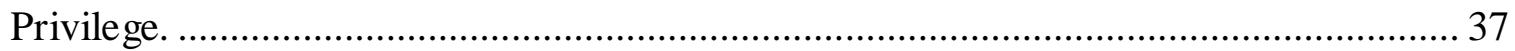

Exploring the G, B and Q in LGBTQ ......................................................................... 39

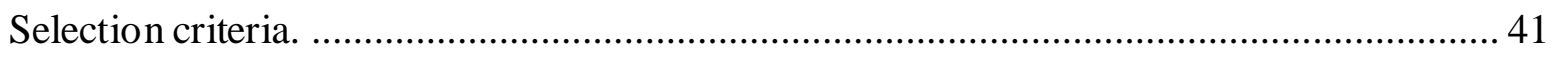

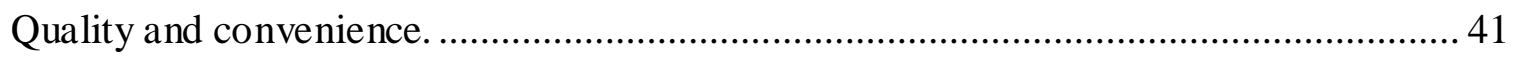

Inclusivity: Significance and construction. …………………………........................ 42

Kindergarten: Quality, convenience and inclusivity revisited. ........................................ 45 
Experiences with EYEs

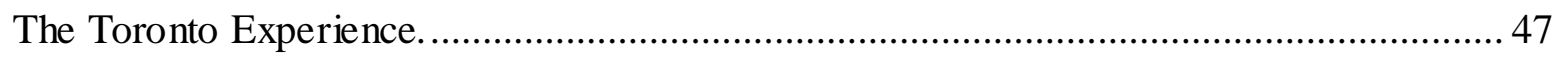

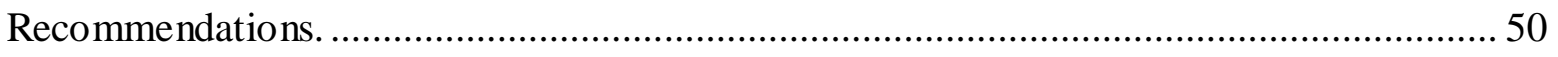

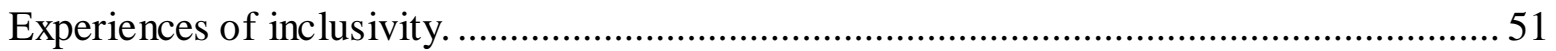

Concerns and experiences with heteronormativity. .............................................. 54

Challenging heteronormativity and improving experiences for LGBTQ parents. ...........57

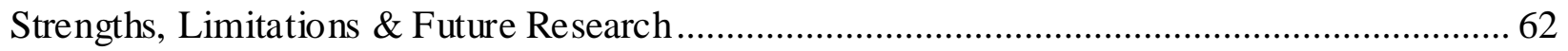

Recruiting from marginalized communities. ......................................................... 66

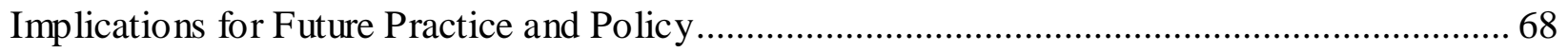

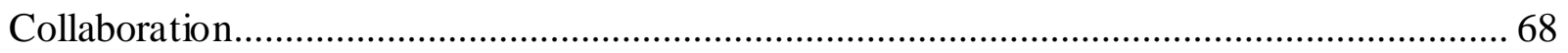

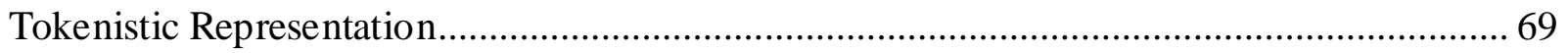

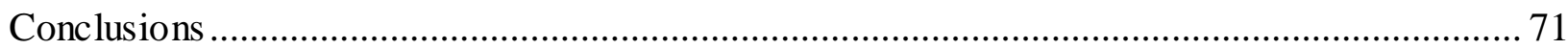

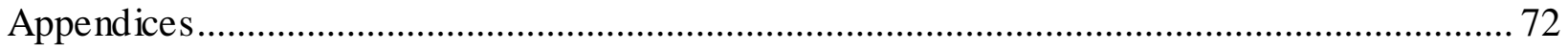

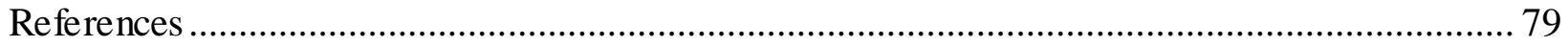




\section{List of Tables}

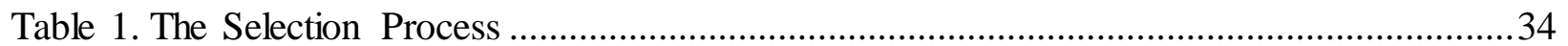

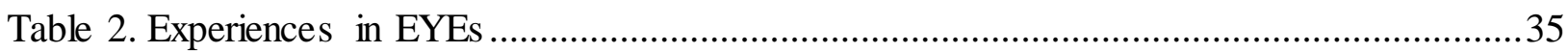




\section{List of Appendices}

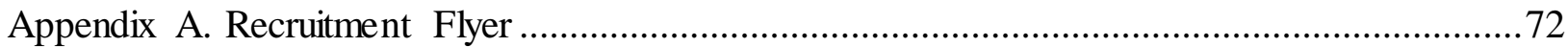

Appendix B. Interview Questions ................................................................................... 73

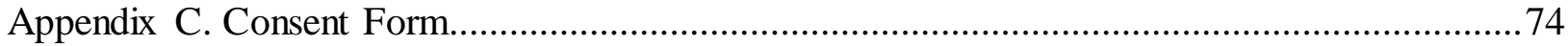

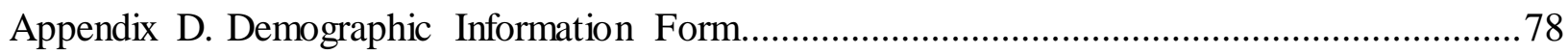




\section{LGBTQ Parents' Experiences with Early Years Environments}

\section{Introduction}

Heteronormativity is a dominant ideology in society that, if unchallenged, silences other sexualities by positioning heterosexuality to be natural and the norm, and causes other sexualities to be the 'other' (Robinson, 2002; Surtees \& Gunn, 2010). Heterosexuality is continuously reinforced in society through practices that make only heterosexuality visible, and therefore make other sexualities invisible (Surtees \& Gunn, 2010). Thus, heteronormativity creates the assumption that everyone is or should be heterosexual (Bryan, 2012), and the culture of sexual minorities is especially silenced.

Early years environments (EYEs) are one of many settings in which heteronormativity is the dominant perspective (Epstein, 2012; Janmohamed \& Campbell, 2009; Kintner-Duffy, Vardell, Lower, \& Cassidy, 2012; Robinson, 2002; Stanley, 2015). For the purpose of this study, EYEs will refer to childcare services where parents can drop off their children during the day, as well as family support programs, in which parents and guardians can accompany their children for the duration of the program. The focus of these services is typically for children ages 0 to 6 years old. In Ontario, Canada, where this study took place, the Ontario Ministry of Education funds various child and family programs, which, according to their website, "provide opportunities for all children to participate in play and inquiry-based programs, and support all parents and caregivers in their roles" (Ontario Ministry of Education, n.d.). Information on child development and other resources are also available to parents and caregivers as needed (Ontario Ministry of Education, n.d.).

Unfortunately, with heteronormativity dominating such services and programs, this means that families headed by lesbian, gay, bisexual, transgender, and queer (LGBTQ) parents 
are often not represented in EYEs. Instead, the focus is usually on families consisting of heterosexual parents (Robinson \& Ferfolja, 2001; Ryan \& Martin, 2000). Various examples of such exclusion include forms that ask for a mother's and father's name, and books and posters that only depict heterosexual parents, to outright discrimination against LGBTQ families by not allowing them access or being homophobic and transphobic when they are present (Fox, 2007; Smolkin \& Young, 2011; Stanley, 2015). The lack of representation and exclusion are important issues to address, especially when looking at the increasing numbers of families headed by LGBTQ parents across North America alone (Averett, Hegde, \& Smith, 2015; Fox, 2007; Janmohamed \& Campbell, 2009), and the Ministry's claim to support all parents and caregivers.

\section{Purpose}

Like many heterosexual parents, LGBTQ parents seek out EYEs, and unfortunately, they must face the additional challenge of dealing with how their family is positioned in these heteronormative environments. Thus, this study seeks to explore the process that LGBTQ parents go through in order to find out what they feel is the "right" EYE for their family, and to share

their experiences in these environments. It is hoped that this information can be used to provide a greater understanding of how all types of families and educators can collaborate to better promote children's learning (Bower \& Klecka, 2009).

A phenomenological approach will be used to study the topic at hand, which will be discussed more in the methodology. But first, the following section presents literature on LGBTQ families in EYEs, with a focus on contextualizing the issue in Ontario. 


\section{Literature Review}

\section{LGBTQ Families in Canada}

The social and political climate has undergone a tremendous shift in Canada in regard to LGBTQ families in that, at one time, LGBTQ individuals had to deny their sexual orientation to keep their children (Epstein, 2012). It was in the 1970s that lesbian mothers became more visible in Canadian society (Epstein, 2012). As activism for the growing lesbian and gay communities increased in the following years, same-sex parents were slowly finding places to go for information, and to attend organized groups, or programs. By the 1990s, LGBTQ families were finally making gains in being more visible and recognized. Programs and organizations for LGBTQ families finally began to appear. In the new millennium, programs and organizations grew in numbers, and legal and social recognition continued (Epstein, 2012).

Unfortunately, LGBTQ families continue to feel excluded in institutions, such as learning and health care facilities, where heteronormativity is dominant (Epstein, 2012). Epstein (2012), a Canadian LGBTQ parenting activist and researcher (Re:searching for LGBTQ Health, n.d.), points out that there is an assumption that queer parenting is a new phenomenon, although LGBTQ parents have existed for years alongside heterosexual parents-LGBTQ parents just remained invisible until the recent past.

\section{LGBTQ Families and EYEs in Ontario}

In a current assessment of Children's Services by the City of Toronto, consultations with families, service providers, and community partners echo the fact that LGBTQ families need program options that are welcoming, inclusive, and safe (Stanley, 2015). Forty-two percent of the 61 survey respondents reported that they had "encountered child care and family support programs that did not adequately demonstrate a commitment" to LGBTQ families (Stanley, 
2015, p. 2). These survey findings show that varying experiences are found in childcare and family support programs due in part to the lack of consistent policies for family inclusion and the lack of a consistent childcare curriculum in Ontario (Stanley, 2015). Thus, LGBTQ families never know what to expect when they are walking into an EYE (Stanley, 2015).

Although EYEs have inconsistent policies regarding inclusion of LGBTQ families amongst different centres and programs, the Ontario government has developed guiding principles for licensed childcare facilities, which are the Early Learning for Every Child Today (ELECT) principles, published in 2007 (Stanley, 2015). The ELECT emphasizes the importance of family and community to help support children, and therefore, relationships need to be established between parents and educators to work together, and respect for different cultures, values, language, and family compositions is promoted (Ontario Ministry of Education, 2014a). The ELECT further notes that EYEs need to encourage positive discussion on inclusion, diversity, and equity because these settings play a vital role in challenging bias and discrimination (Ontario Ministry of Education, 2014a; Stanley, 2015). EYEs "can take into account the differences each child and family brings into an early childhood setting including appearance, age, culture, ethnicity, race, language, gender, sexual orientation, religion, family environment, and developmental abilities" (Ontario Ministry of Education, 2014a, p. 5). Finally, the ELECT highlights the importance of being knowledgeable and responsive to children and their families, in order to "establish social and physical environments where children thrive" (Ontario Ministry of Education, 2014a, p. 13).

In 2014, the Ontario government published another document to build on ELECT called How Does Learning Happen? (Stanley, 2015). This mandatory document was developed for EYEs for the purpose of self-reflection and to guide programs by outlining the importance of 
"views about children, the role of educators and families, and the relationship between and across these three factors" and how these aspects influence the curriculum (Stanley, 2015, p. 7). How Does Learning Happen? also emphasizes four essential factors for child development, which are belonging, well-being, engagement, and expression. The aspect of belonging is particularly relevant for LGBTQ-inclusivity in a number of ways (Stanley, 2015). For example, the Ontario Ministry of Education (2014b) states that "fostering good relationships with children and their families is the single most important priority for educators in early years programs" ( $\mathrm{p}$. 24). Additionally, "children's sense of belonging and feelings of security are also strengthened when they have opportunities to make and explore connections between home and the early childhood program" (Ontario Ministry of Education, 2014b, p. 24). Although explicit terms such as 'LGBTQ' are not used in the document, early years staff and administration must recognize that families exist in many forms, and be prepared to apply the guidelines to all families.

In addition to these provincial documents for EYEs, a number of national and provincial policies also exist that are meant to protect LGBTQ parents against discrimination, such as the Canadian Human Rights Act:

For all purposes of this Act, the prohibited ground of discrimination are race, national or ethnic origin, colour, religion, age, sex, sexual orientation, marital status, disability and conviction for an offence for which a pardon has been granted or in respect of which a record suspension has been ordered. (Canadian Human Rights Act, 1985, p. 6)

Furthermore, the Ontario Human Rights Code states the following:

Every person has a right to equal treatment with respect to services, goods and facilities, without discrimination because of race, ancestry, place of origin, colour, ethnic origin, 
citizenship, creed, sex, sexual orientation, gender identity, gender expression, age, marital status, family status or disability. (Ontario Human Rights Code, 1962, p. 3)

It is important to note that gender identity and gender expression were recently added to the Ontario Human Rights Code in 2012, with policymakers still fighting for the change in the Canadian Human Rights Act (Donalto, 2015; Ontario Human Rights Code, 1962; 2012). Nevertheless, despite this legislation, the research shows that LGBTQ families are still experiencing discrimination in EYEs. This issue is not isolated in Canada, but exists in other countries as well. The following sections discuss literature from various researchers in Australia, New Zealand, the United States, and Canada, with an emphasis on the last ten years of research on the topic LGBTQ families in EYEs.

\section{Heteronormativity in EYEs}

Heteronormativity can exist in a multitude of ways, on a conscious and unconscious level, in EYEs (Fox, 2007). An example of conscious heteronormativity is active resistance of including LGBTQ issues in educational contexts, which could be related to religious, moral and cultural beliefs about LGBTQ relationships (Fox, 2007; Robinson, 2002). Robinson (2002), an Australian researcher, argues that this type of resistance is also located in homophobic and heterosexist discourse. Heteronormativity can act on an unconscious level when one argues that sexuality is considered to be a private matter that is to remain in family conversations, or in adults' private lives, rather than the responsibility of early childhood institutions. However, mock heterosexual weddings, mother/father and girlfriend/boyfriend play go unchallenged in EYEs (Fox, 2007). Early childhood educators even have a tendency to assume that play involving such couplings is natural and is rarely questioned (Robinson, 2005). Thus, sexualities 
that deviate from heterosexuality are silenced, and 'heterosexuality becomes the 'public' voice, definition and representation of 'normal' and natural sexuality" (Robinson, 2002, p. 423).

Robinson (2002) further argues that early childhood educators often assume that LGBTQ families "are not part of their clientele, community or members of their own staff" (p. 428). One mother expressed her frustration at society's lack of seeing beyond heterosexual norms in an Australian study conducted by Skattebol and Ferfolja (2007), in which lesbian mothers were interviewed about their experiences with children's services. This particular participant discussed how she and her partner were seen as a family unit, but never as being in a lesbian relationship. Instead, they were often seen as a mother and her grandmother or a mother and her sister (Skattebol \& Ferfolja, 2007), which clearly demonstrates the workings of heteronormativity in EYEs. Furthermore, an American study found that same-sex parents have reported to not have high expectations of inclusive environments due to high levels of heteronormative thinking with preschool teachers and administrators (Glass, Willox, Barrow, \& Jones, 2015).

In terms of the learning materials in EYEs, Australian researchers, Riggs and Augoustinos (2007), found that most of the storybooks reinforced a White heterosexual norm for parenting. American researchers, Smolkin and Young (2011), also found that EYEs typically had literature that represented opposite-sex, two-parent households, and these books were read, shared, and discussed regularly. If such instances of heteronormativity continue to go unexamined and unchallenged, then the goal of the early childhood field of "intentionally including all children and families in early childhood programs" is hindered (Kintner-Duffy et al., 2012). Unfortunately, many LGBTQ families who participate in EYEs feel pressured to remain silent and invisible due to such dominant discourses (Robinson, 2002). However, LGBTQ families have also challenged heteronormativity by being open about their sexuality and 
family structure. Various instances of this resistance are cited in the literature, which is discussed in the following section.

\section{Challenging Heteronormativity}

One of the most common ways parents in the literature challenged heteronormativity in EYEs was to disclose their sexuality and family structure to staff. New Zealand researchers, Gunn and Surtees (2009), who study heteronormativity in early childhood education, argue that being open and positive of one's family structure will lead to greater acceptance of diverse families. Skattebol and Ferfolja's (2007) findings support this, emphasizing the need for disclosure as a way for lesbian mothers to support their children. More specifically, one mother stated that disclosure acts as a support for her daughter because if they show shame as lesbian parents, then their daughter will be shamed. Ultimately, it is about instilling feelings of pride in one's family, in addition to challenging heteronormativity (Skattebol \& Ferfolja, 2007). Lee's (2010) interviews with lesbian mothers (2010) in New Zealand found similar results in which mothers were generally open with educators about their family structure, and some even directly asked educators how they felt about same-sex families. Like the mothers in Skattebol and Ferfolja's (2007) study, these mothers challenged heteronormativity by modelling pride in their family, socializing with other queer families, and talking to their children about diverse families (Lee, 2010). Goldberg's (2014) American study, which looked at the extent to which gay, lesbian and heterosexual adoptive parents disclose their family structure to teachers, also found that parents were open about discussing their family structure in their children's preschools. An interesting finding that Goldberg (2014) points out is that the gay and lesbian parents who did not disclose their family structure are from more rural areas, with half living in the southern 
United States. Goldberg (2014) argues that this demonstrates the importance of "geographic and social context in shaping lesbian and gay parents' openness about their sexuality" (p. 678).

Despite these instances of honest and open disclosure, Robinson (2002) argues that gay and lesbian families may view 'coming out' to their children's educators as extremely difficult and a potential risk because of the dominant heteronormative discourse in educational settings. So while mothers were able to be open about their family composition, they also discussed the importance of attending EYEs that had been recommended to them by friends and family because these environments were more likely to be inclusive of diverse families (Lee, 2010). Potential negative reactions to their family structure would then be lessened or avoided (Lee, 2010). Thus, gay and lesbian families often look for EYEs that express a commitment to diversity and difference, so that their children and family will not be discriminated against (Robinson, 2002).

Parents further challenged heterosexual norms in children's services by requesting learning materials that represented same-sex families (Skattebol \& Ferfolja, 2007, p. 15). Some of the mothers went so far as to purchase the books themselves to ensure availability of such resources. Unfortunately, even when these resources became available for the centres to use, they were not easily accessible because they were locked up and only put out on days when the staff thought to take them out. One mother in Skattebol and Ferfolja's (2007) study noted that staff at her centre claimed that they were unaware of where to even obtain such resources. However, centres included in this study were located in a geographical location where there were many LGBTQ resources around. Skattebol and Ferfolja (2007) argue that these educators simply were not making an effort to find such resources. Nevertheless, even when the resources were available, the mothers themselves had to push the educators to make them more visible 
(Skattebol \& Ferfolja, 2007). LGBTQ families in Toronto discussed similar situations, in which they brought their own resources to programs and centres in order for their families to be represented (Stanley, 2015). Visibility through the learning materials at EYEs is clearly of importance to LGBTQ parents.

Parents also argued that it is not enough to represent the LGBTQ community in a "oneoff" or tokenistic way because it positions them as a "highly visible Other to "normal' families" (Skattebol \& Ferfolja, 2007, p. 16). Janmohamed and Campbell (2009), Canadian researchers who have contributed a great deal to LGBTQ research in the early childhood field, support this latter point by asserting that exploring LGBTQ issues should be continuous throughout the year for EYEs, rather than just during Gay Pride month in June, for example. Robinson (2002) argues that these problems of proper representation occur because inclusion of LGBTQ families in the early years curriculum 'tends to rely on the educator's perception of what they consider relevant and appropriate to the children in their settings, as well as their own personal comfort levels in addressing such issues" (p. 429). In other words, since early years policies mandating the

specific inclusion of LGBTQ families and how to do so effectively are lacking in Ontario, EYEs can provide very different experiences (Stanley, 2015). Consequently, the selection process for EYEs can become a potentially challenging process for parents.

\section{Preschool Selection Considerations}

Goldberg and Smith's (2014) American study is the first to look at "school selection considerations and perceived mistreatment among lesbian, gay, and heterosexual adoptive parents of preschool-aged children" (p. 72). Various factors for school selection were assessed by parents, in which educational philosophy was found to be the most important for the sample as a whole and for each group in the study. Overall, cost of attending the school was the next 
priority on the list for heterosexual parents. For lesbian and gay parents, the "gay-friendliness" of the school was the second highest priority, with cost closely behind. How exactly "gayfriendliness" was defined in Goldberg and Smith's (2014) study, and assessed by parents, is unclear. Nonetheless, past research has indicated that LGBTQ parents look for progressive, gayfriendly schools to try and decrease the chances of their children being exposed to stigma and discrimination based on their family structure (Casper \& Schultz, 1999; Lee, 2010; Mercier \& Harold, 2003; Robinson, 2002). Next on the list of considerations were racial diversity followed by location. A small number of the sexual minority parents discussed the importance of having other LGBTQ families present in selecting a school, and a smaller number of the overall sample mentioned the presence of adoptive families (Goldberg \& Smith, 2014). Goldberg and Smith (2014) argue that these latter two factors did not take higher priority because parents understood that this would not be easy to find in schools.

Goldberg and Smith's (2014) further analysis of their results found that "parents with less income were more likely to consider cost in selecting a school" (p. 73), and "less educated parents were more likely to consider location in choosing a preschool" (p. 73). Additionally, parents with more education were more likely to consider racial diversity and the presence of other adoptive families in choosing a school (Goldberg \& Smith, 2014). More specifically with lesbian and gay parents, more educated parents were more likely to consider the presence of other LGBTQ parents and the gay-friendliness of the school. In regard to school mistreatment due to sexual orientation, lesbian and gay parents who saw their communities as "less gayfriendly were more likely to perceive school bias due to sexual orientation" (Goldberg \& Smith, 2014, p. 73). Goldberg and Smith (2014) make reference to Bronfenbrenner's ecological theory 
here, arguing that this finding indicates how the social context may influence more local school attitudes and practices.

Lee (2010) notes that choosing an EYE was a complex process for her participants because of their family composition. The mothers were careful with their choice and used several strategies to help find their ideal service, such as considering others' recommendations for inclusive centres, being open about their family composition, and observing the quality of the interactions between teachers and children. As mentioned earlier, the use of recommendations may be more important for LGBTQ families than for heterosexual parents because of the more potential negative reactions that can occur with their family structure (Lee, 2010). By listening to recommendations from family and friends and actively looking for inclusive centres that are committed to diversity, it can lessen the discrimination that LGBTQ families and their children may encounter (Robinson, 2002).

\section{Improving the Experiences of LGBTQ Families in EYEs}

A number of common suggestions are found in the literature, across the differing countries, to help improve the experiences of LGBTQ families in EYEs. These include having discussions and learning materials that represent various family structures, such as same-sex families, and proper support and training in working with LGBTQ families for administrators and staff (Fox, 2007; Goldberg, 2014; Skattebol \& Ferfolja, 2007; Stanley, 2015; Szalacha, 2004).

One mother in Skattebol and Ferfolja's (2007) study stated that simply seeing images of different family structures would make her feel safe when entering a childcare setting; "just seeing those images there and knowing that it is just part of the daily visual input of those children, that would make me feel [accepted]" (p. 14). Participants in Goldberg's (2014) study 
went beyond visual images in the environment, suggesting that childcare services incorporate discussions on family diversity into the curriculum, as well as the availability of inclusive books, and activities that are inclusive to all types of family structures. Additionally, families felt that family activities, such as potlucks, would help to build a community among parents. A challenge reported by a few participants is the lack of comfort that other parents had with LGBTQ families, and this may help to improve those relationships (Goldberg, 2014, p. 679).

Fox (2007) notes a small but important change they made when they became Director of a university childcare centre, which was changing enrolment forms to be more inclusive of diverse families. More specifically, the forms initially asked for the mother's and father's name, and they instead changed it to the name(s) of a parent/guardian. However, while administrators of a childcare centre may be accepting of differences in sexuality, the staff who work with the families on a daily basis may not be so welcoming or well-versed in working with such families (Skattebol \& Ferfolja, 2007). Skattebol and Ferfolja (2007) argue that this gap needs to be acknowledged in order to provide quality care for LGBTQ families. Conversely, Stanley (2015) reports that families in Toronto discussed the importance of Directors and management at centres being supportive of and helping with efforts for inclusion:

Senior management, directors, and supervisors need to be active and committed to the efforts [for inclusion], to demonstrate to other staff the importance and commitment to new training or policies; if supervisors and directors are not demonstrating commitment to the initiative, staff will not be motivated to make a true effort (Stanley, 2015, p. 13). Overall, the research shows that investment in inclusion for all families has to occur from behind-the-scenes as well as on the frontline. 
Another essential improvement that the literature discusses is the pre-service and inservice training that educators get on LGBTQ issues (Fox, 2007; Stanley; 2015; Szalacha, 2004). Goldberg (2014) found that gay and lesbian parents who reported challenges related to their family structure had to do with the lack of training that educators had working with LGBTQ families. This was especially prominent in the rural areas of the United States. Averett et al. (2015) further found that while early childhood educators generally hold a positive view towards working with LGBTQ parents, they do not feel prepared to do so on an educational level. Surtees and Gunn (2010) also argue that resources are lacking for childcare services and elementary schools to become more LGBTQ-inclusive. Research by the City of Toronto's Children Services found similar results regarding training (Stanley, 2015). For example, LGBTQ families reported being welcomed and educators making changes to be more inclusive of their families, but that there was simply a lack of knowledge and proper resources to do so. As one stakeholder stated, "people are well-intentioned, but clueless" (Stanley, 2015, p. 10). One recommendation to improve training in family inclusion is to work collaboratively with members of the LGBTQ community, whenever possible (Stanley, 2015).

Unfortunately, Averett et al. (2015) point out that in conducting their review of the literature, many of the improvements that could be made for EYEs to be more LGBTQ-friendly have been suggested as far back as 1990, and are still being suggested in literature in 2010. Thus, there has clearly been a lack of progress in the inclusion of LGBTQ practices in EYEs, specifically in the inclusion of LGBTQ-friendly symbols, books and language (Averett et al., 2015). Averett et al. (2015) claim that this then leads back to the initial problem with the lack of training. However, Fox (2007) also argues that it is the responsibility of the educator to go beyond what they have learned in their formal education in order to meet the needs of LGBTQ 
families. This argument is important to highlight because, ultimately, inclusion of all types of families involves a change in attitude; therefore, educators must genuinely want this change to occur and actively seek out ways to do so (Stanley, 2015). One Canadian participant perhaps said it best, stating that inclusivity is "not a matter of putting more books in the classroom, it is the harder work of changing attitudes" (Stanley, 2015, p. 3).

\section{Attempts at Inclusion}

It is important to note that the research on LGBTQ inclusivity in EYEs has not all been negative. Glass et al. (2015) interviewed a number of parents from different centres who did feel that their child's teachers or the administration were actively going above and beyond their expectations to be inclusive of their family in the learning environment. Examples of these positive experiences included teachers who changed the language used when discussing families, discussing different types of families with the children, and calling same-sex parents by the names the children call them. Glass et al. (2015) point out that while these moderate shifts to integrate LGBTQ families was very much appreciated by the parents, the larger shifts of including LGBTQ families was not occurring. Furthermore, it was a "careful balance between integrating gay and lesbian families without making ripples or without being proactive and taking a social stance" (Glass et al., 2015, p. 21).

An example of a "larger shift," or more proactive change, would be talking about LGBTQ families even if those families are currently not attending the centre or simply not visible, which only one educator was doing in Glass et al.'s (2015) study. Stanley (2015) argues that all centres need to be prepared to have LGBTQ families, or to recognize that they may already be serving LGBTQ families, even if those families have not disclosed such information. Stanley (2015) points out further that 'the idea that a program does not have any [LGBTQ] 
parents or children and thus no reason to take action, an attitude which is commonly presented by staff, represents an attitude of ignorance, as simply because no families have identified themselves does not mean that the [LGBTQ] community is not represented" (p. 15).

\section{Gaps in the Research}

Averett et al. (2015) note that more studies are needed that look specifically at early childhood samples because the literature they found to examine EYEs were often within studies that consisted of a larger mixed-age group of children. Additionally, Averett et al. (2015) discuss the fact that most research about LGBTQ families and EYEs have samples that are only lesbian mothers. This is evident even in the writing of this literature review (Lee, 2010; Skattebol \& Ferfolja, 2007). The literature emphasizes the importance of gaining a better understanding of the LGBTQ community's position in the field by studying gay fathers, as well as bisexual, transgender, and queer parents (Averett et al., 2015; Cloughessy \& Waniganayake, 2014). Epstein, Duggan, and Veldhoven (2006) support the latter statement, noting that GBQ men specifically face many negative stereotypes as parents, and thus, GBQ fathers need to be represented more in social programs and services, which could be aided by increased representation in research. Finally, Goldberg and Smith (2014) note in their study on preschool selection considerations that their sample was fairly affluent, and therefore, future studies should examine samples that, for financial or geographical reasons, "have less access to progressive and gay-friendly schools" (p. 73).

The current study hopes to address some of these gaps in the research in the various ways. For one, it is intentionally looking at EYEs exclusively, and therefore, specifically targeting parents who have children from a specific age group The current study is also being conducted with the hopes of obtaining a sample that is not financially homogenous, and having a 
mix of members from the LGBTQ community, rather than just lesbian mothers. Additionally, discussions of relocating and travelling will be discussed with families, to see how this may play a role in finding an appropriate EYE. More details of how these gaps will be addressed will be discussed in the methodology.

\section{Theoretical and Conceptual Frameworks}

This study is being conducted through a Queer Theory framework, which, according to Creswell (2014), looks at individuals who identify as part of the LGBTQ community. Gamson (2000) states that research that uses Queer Theory "does not objectify individuals, is concerned with cultural and political means, and conveys the voices and experiences of individuals who have been suppressed" (as cited in Creswell, 2014, p. 65). Furthermore, Taylor and Blaise (2007) describe Queer Theory as "theorising gender and challenging its binary framings" (p. 1). A very important concept in Queer Theory is heteronormativity, which has been discussed previously in this study, and will be elaborated on here briefly.

Heteronormativity is heavily constructed through normative gender binaries (Taylor \& Blaise, 2007). This means that boys and girls have to behave according to what society considers as 'normal' behaviour for boys and girls. Butler (1990) refers to this normalization of behaviour as understanding gender through the 'heterosexual matrix.' Judith Butler is an essential contributor to Queer Theory and coined the term 'heterosexual matrix' to describe the way in which gender is "systematically, socially, and relationally constructed" (Taylor \& Blaise, 2007, p. 2). Butler (1990) agues that heterosexuality is enforced through "rewards for appropriate gendered and heterosexual behaviours and through punishments from deviations from the conventional or 'normal' ways of being either a girl or a boy" (as cited in Taylor \& Blaise, 2007, p. 2). Hence, Queer Theory frames the current study by examining the ways in which LGBTQ 
parents position themselves in a heteronormative society, and in their children's institutions that enforce normalizing discourses (Bower \& Klecka, 2009).

With regard to my conceptual framework, I am operating from a transformative perspective. This means that the current research focuses on the "lives and experiences of diverse groups that have traditionally been marginalized" (Mertens as cited in Creswell, 2014, p. 10). More specifically, there is particular interest in how these groups have been "constrained by oppressors and the strategies that they use to resist, challenge, and subvert these constraints" (Mertens as cited in Creswell, 2014, p. 10).

I am also operating from a children's rights perspective. This perspective does not appear to be focused on frequently in the literature on LGBTQ families and EYEs, except for research conducted by Australian researchers, Cloughessy and Waniganayake (2014). Prior to reading their research, I had taken a Social Research with Children course that emphasized children's rights. During that course, I chose to focus specifically on children's perceptions of different family structures. From there, I started to wonder how children from LGBTQ families would learn about their own families in a formal educational setting, if their families are not represented. Cloughessy and Waniganayake (2014) point out that "educators are guided by legislative and other regulatory requirements as well as professional documents that demand respectful interactions with children and adults from diverse backgrounds" (p. 1269). For instance, Article 2 from the United Nations Convention on the Rights of the Child, to which Canada is a signatory, explicitly states the anti-discrimination rights of a child and a child's parents:

Article 2.1: States Parties shall respect and ensure the rights set forth in the present Convention to each child within their jurisdiction without discrimination of any kind, 
irrespective of the child's or his or her parent's or legal guardian's race, colour, sex, language, religion, political or other opinion, national, ethnic or social origin, property, disability, birth or other status. (United Nations, 1989)

Article 2.2: States Parties shall take all appropriate measures to ensure that the child is protected against all forms of discrimination or punishment on the basis of the status, activities, expressed opinions, beliefs of the child's parents, legal guardians, or family members. (United Nations, 1989)

Given this information, it is important to note that homophobia in educational settings is not just "perpetuated on people who have LGBT identities (or presumed to have LGBT identities) but also towards those who have parents who identify as LGBT" (Pohan \& Bailey, 1998; Ray \& Gregory, 2001). Glass et al. (2015) also argue that children may begin to feel that their family is not as valued as other families, if educators are not discussing and appreciating different family structures. Therefore, educators should ensure that every child feels welcome and included in their educational setting, which involves understanding children's families. By gaining the perspective of LGBTQ parents on inclusion in EYEs, this study seeks to provide insight into what creates a genuinely inclusive EYE.

\section{Social Location}

As a member and advocate of the LGBTQ community, I am drawn to the Queer Theory framework and the transformative perspective for various reasons. I want to ensure that the voices of the LGBTQ community are represented in research, and that every opportunity is taken to help educate society, particularly in my field of early childhood, about the LGBTQ community. It is also my way of challenging heteronormativity by making LGBTQ voices more visible. 
My social location is important to discuss because of the potential bias I may have when analyzing and interpreting my data. For instance, my personal bias may cause me to place emphasis on the negative experiences of parents participating in my study because I may connect to those stories emotionally, and retelling those stories in my findings may also create a more emotional connection with my audience. This bias of emphasizing negative experiences quickly came to me just in the writing of the literature review, when I realized that I had not reported on any positive experiences LGBTQ families were discussing, which, although far and few between, did exist. Similarly, I may interpret certain participant statements as negative exclusion when they may view it as otherwise because of the negative perspective I have on LGBTQ inclusion in the early childhood field. Thus, I must work on entering the interview process in a neutral and open-minded headspace, and continue to do so when analyzing and interpreting my data. This will also allow me to ask participants to interpret their experiences themselves, rather than having me interpret stories automatically from a negative point of view. Recognizing these biases aligns with a fundamental tenet of phenomenology, to come from a "fresh and unbiased" perspective, which is the approach guiding this research (Wertz, 2005). Lastly, by not being a parent myself, my perspective on their stories may not be the same as someone who is a parent. At the same time, my social location may also be beneficial in several ways. For example, there will be genuine interest when conducting my interviews with parents and when retelling their stories because I am very passionate about advocating for the LGBTQ community. I want to appropriately capture the feelings they have experienced to ensure that those who have not experienced such stories can gain an understanding of what it is like to experience exclusion in today's society, and also what it feels like to overcome challenges when one is a part of a marginalized community. 
Throughout my graduate studies, I have tried to learn and write about many of the issues that exist in the LGBTQ community in relation to the early childhood field. I have explored topics such as gay educators in EYEs and primary grades, LGBTQ media portrayals for children, how children view different family structures, and the inclusiveness of the elementary school curriculum from a mostly Western perspective. A perspective I did not tackle more directly is that of LGBTQ parents, which has led me to this current study. As someone who hopes to have a family with my partner in the next few years, I believe this research will be of immense value to me, and I hope it will be for other LGBTQ families as well.

\section{Research Questions}

Before discussing the methodology of the current study, it is essential to keep the research questions in mind, which are as follows:

1. What is the process that LGBTQ parents go through in seeking an EYE for their child or their family, in a generally heteronormative society?

2. What are their experiences during the selection process and when partaking in an EYE?

\section{Methodology}

The following sections will discuss how the current study was conducted and a justification for the approach taken. Considering my research questions, qualitative research seemed to be the most appropriate way to explore these questions. Qualitative research is defined as seeking to explore and understand "the meaning individuals or groups ascribe to a social or human problem" (Creswell, 2014, p. 4). This method was chosen in order to discuss "the experiences of individuals about a phenomenon as described by participants" (Creswell, 2014, p. 14), which is a type of qualitative research approach called phenomenological research. Magrini (2012) also defines phenomenology as a "method of recording and interpreting 'lived 
experience' through vivid and detailed descriptions" (p. 2). Like Glass et al.'s (2015) research, this study seeks to explore the phenomena of being an LGBTQ parent seeking and being a part of an EYE. Additionally, Creswell (2014) claims that the qualitative approach is effective for phenomenon in which little research has been done. As previously argued, while the topic of LGBTQ parents and EYEs has been the subject of research in this province, very few such studies have been carried out.

\section{Recruitment Process}

After receiving approval from the Research Ethics Board (REB) at Ryerson, I began recruitment of participants. Initially, I was to recruit at one site, but given a low response rate (the reasons for which are discussed below), I sought and was given approval from the REB to add additional sites.

Sites. Recruitment occurred at a number of places, including The 519's Family Resource Centre (FRC), Sherbourne Health Centre's LGBTQ Parenting Network (LGBTQPN), and Ryerson University's Early Learning Centre (ELC), all located in downtown Toronto, Ontario.

The 519's FRC. The 519's FRC is a family support program for families with children age 0 to 6 years. The program provides "early learning activities, music and movement, creative experiences, nutritious snacks, and parent education" (The 519, n.d.). The program runs from Tuesday to Friday, $10 \mathrm{am}$ to $1 \mathrm{pm}$, as well as Tuesdays from 5:30pm-7:30pm (The 519, n.d.). Every second Saturday of the month, from 9am to 1pm, the FRC hosts a Queer and Trans Family Event to celebrate LGBTQ diversity, and designed specifically for queer and trans families (The 519, n.d.). As for The 519 itself, it is a City of Toronto agency that is "committed to the health, happiness and full participation of the LGBTQ community" (The 519, n.d.). 
I was first introduced to The 519 by a professor and faculty member of the Early Childhood Studies graduate program at Ryerson University as a potential site to use for a social justice assignment, in which students were to assess a program that related to the early childhood field. After doing some research on The 519, and visiting their FRC, I was very impressed by their inclusivity and welcoming atmosphere. For example, I was welcomed by friendly faces of student volunteers and staff, and immediately noticed all the LGBTQ-friendly images in the centre. The Program Director also showed me all the inclusive books available in the centre, such as books depicting families with same-sex parents. Additionally, I observed their circle time, which involved songs that used non-gendered language, songs that were sung accompanied with sign language, and songs that were sung multiple times in different languages-which was easily done with the various cultures that were present in the centre. It was, quite simply, an amazing experience. This quickly translated into me applying for a volunteer position at the centre, to which I was later successful.

By becoming a volunteer at The 519's FRC, I thought it would be a valuable opportunity to immerse myself in a resource that would not only be beneficial to myself, but is beneficial to the LGBTQ community. It was also important for me to get more acquainted with the LGBTQ community, as well as the local community, if I planned to do research within the community. By being a volunteer, this would allow me to be more of an insider, rather than coming in as an outsider interested in researching its community members (Christensen, 2004). At the same time, becoming a volunteer at the FRC could potentially have a disadvantage in my being able to actively recruit participants because participants might feel obligated to participate in my study due to my connection with the centre, and because I may have formed prior relationships with potential participants. In order to reduce feelings of obligation, the REB suggested having the 
staff advertise my study, and to have flyers advertising the study displayed around The 519; I was not to approach parents myself. It is also important to note at this point that the FRC was initially the only site for recruitment because it was the only child and family based service I had heard about that is known for its strong inclusivity of the LGBTQ community. Past research in Toronto also found that LGBTQ parents often rely specifically on The 519, even if it is a far distance, because of its focus on inclusivity (Stanley, 2015).

Unfortunately, while the staff were helpful in contacting potential participants, there was a very low response rate. A total of three parents expressed their interest in participating, but due to time commitments and the fact that I was recruiting around the end of children's school year, Pride month, and the Canada Day long weekend, scheduling an interview was a significant challenge. Parents also expressed their hesitation to participate due to their beliefs that they might not be suitable given their personal experience, or lack thereof, with the topic. Follow-ups with these participants indicated continued interest, but again, a date to hold the interview was never confirmed. Given these occurrences and the limited amount of time to complete this study, additional sites were sought out.

Sherbourne Health Centre's LGBTQPN. The LGBTQPN was recommended to me by one of the parents contacted by The 519 staff for my study. The LGBTQPN is a program run out of the Sherbourne Health Centre, which supports LGBTQ parenting "through training, research, resource development and community organizing" (Sherbourne Health Centre, n.d.). The Sherbourne Health Centre "delivers primary healthcare services to LGBT communities in Toronto; provides information, resources, and capacity building to communities across Ontario; and community-based programs to queer and trans youth in Toronto" (Sherbourne Health Centre, n.d.). While I did receive confirmation of approval for my study to be advertised by the 
LGBTQPN on their website, social media networks, and so forth, I was unsure of where exactly these advertisements were located. Again, given the time constraints, I did not follow-up with this, and continued to look for other sites for recruitment.

Ryerson University's ELC. Finally, Ryerson University's ELC was added as a site upon the recommendation from my supervisor and approval from the ELC Program Director. The ELC is Ryerson's 'licensed laboratory early learning and childcare centre. It is a full-day childcare and early learning program for 66 children from ages 18 months to six years" (Ryerson University, n.d.). The ELC is open from Monday to Friday, $8 \mathrm{am}$ to 5:30pm. The children are divided into four different rooms, which include two toddler rooms (18 months to 30 months) that can serve up to 15 children, a preschool room (30 months to four years) that serves 16 children, and a kindergarten/preschool room (three to five year olds) that serves up to 16 preschoolers and about 10 kindergarteners (Ryerson University, n.d.).

Sampling strategies. First and foremost, sampling was conducted through a purposive manner because I wanted a specific group of individuals to participate in the study (Maxwell, 2009), which, in this case, was LGBTQ parents of young children. As previously mentioned, a gap in the research is the voices of gay fathers, as well as bisexual, transgender and queer parents; thus, an effort was made to recruit such individuals by searching online for specific LGBTQ parenting groups based in the General Toronto Area (GTA). The GTA includes central Toronto, as well as neighbouring cities, such as Etobicoke and North York. The GTA is also frequently used to refer to surrounding regions, such as Peel Region, which includes cities like Mississauga and Brampton, and York Region, which consists of Markham and Newmarket, and so forth (Campbell, 2016). 
In order to recruit more participants, particularly from those groups missing in the research, snowball sampling was also used. This involves asking initial participants if they know others who may be eligible to participate in the study (van den Hoonaard, 2014). I used this in combination with purposive sampling by explicitly telling participants that gay, bisexual, transgender, and queer parents' voices are not represented enough in the research, and if they knew any individuals who identified as so, while meeting all the other inclusion criteria to participate.

\section{Sample}

While Collingridge and Gantt (2008) recommend having 10 participants for a phenomenological study, due to time constraints and challenges in recruiting, a total of five participants were included. Creswell (2014) does confirm that three to ten participants is a typical number for phenomenological research.

Pseudonyms have been assigned to protect parents' identities. Three of the mothers identify as lesbian and are married to their female partner: Ariana, mother to a 4-year-old and a newborn; Britney, mother to a 7-year-old and a 4-year-old; and Lana, mother to a 4-year-old. Troye is a gay father, married to his husband, with a 6-year-old child. Finally, Selena identifies as bisexual and queer, and is married to her queer husband. She is a mother to a 2-year-old child who is being raised gender-open, which means she and her partner are not following gender stereotypes based on their child's sex assigned at birth (Rainbow Health Ontario, 2016). Thus, rather than using personal pronouns such as he/him or she/her that are used for individuals who identify as male or female, the correct pronouns to use for their child is they/them (Rainbow Health Ontario, 2016). This is an essential component to Selena's experiences, and therefore, important to keep in mind when reading about her perspective. 
All participants reported being White, having a Master's degree as their highest education level, and being married to their partner. All mothers reported being in the 30-39 age range, and the one father indicated being in the 40-49 age range. Three parents reported an annual income between $\$ 50,000$ - $\$ 74,999$, with the other two parents reporting an annual income of $\$ 75,000$ $\$ 99,999$.

Inclusion criteria. In order to be eligible for participation, individuals have selfidentified as part of LGBTQ community, be at least 18 years of age, and be the guardian of a child aged 0 to 6 years for which they sought out an EYE in the past six years. Participants were not required to be currently using an EYE at the time of participation (see Appendix A for the recruitment flyer).

Exclusion criteria. Although I did not explicitly state limitations to which participants resided and/or cities where they used an EYE, as the data began coming in, I thought it best to limit the study to participants in the GTA. By doing so, I would be able to keep the context of the study in the area of southern Ontario. All participants ended up residing and using EYEs specifically in Toronto, and thus, this contextualizes the study in one urban setting, particularly well-known for its diversity (Rayside, 2014).

\section{Procedure}

Semi-structured telephone interviews were conducted for the current study. Interviews were selected as the method of data collection because they are an effective way to study "phenomena from the perspective of those who experience the phenomena" (Collingridge \& Gantt, 2008, p. 393), which also relates back to taking a phenomenological approach. Creswell (2014) also makes the point that the researcher is considered a key instrument in qualitative research, and one way to be an effective qualitative researcher is by interviewing participants. 
One-on-one interviews were selected, rather than focus groups, in order to avoid concerns of confidentiality between participants, as well as due to issues with scheduling parents to gather for a specific place and time. Semi-structured interviews were used in order to have a clear intent about what information was being sought after from participants, but with enough openendedness to allow participants to tell their stories and give their perspective (Creswell, 2014) (see Appendix B for pre-set questions). Participants were asked to provide a preferred location to be interviewed, and with the first few participants, this ended up being a telephone interview. Thus, telephone interviews became an initial suggestion along with an in-person interview, when potential participants contacted me expressing their interest.

Once participant interviews were confirmed, the consent form and demographic information form were emailed out 24 hours prior to the interview (see Appendix $\mathrm{C}$ for the consent form and Appendix D for the demographic information form). These were then emailed back to me at their earliest convenience. When the phone interview began, with their permission, participants were put on speaker phone in order to record the call with another mobile device for later transcription of the interview. The duration of the phone interviews were generally 20 minutes long, with the exception of one interview lasting about 45 minutes in length. This time length is comparable to past research where individual parents were being interviewed, lasting from about 15 minutes in length to an hour (Bower \& Klecka, 2009; Lee, 2010). Additionally, De Vaus (1991) argues that telephone interviews should be fairly short because fatigue or inattention may occur after about 30 minutes.

To ensure accurate representation of participants' perspectives, they were given an option to review their transcripts. Only one participant chose to undertake this process, but did not 
return the transcript. Thus, the original transcription from all participants was used for data analysis.

Pros and cons of telephone interviews. A primary concern for conducting telephone interviews is "the lack of interaction between the interviewer and participant" (Trier-Bieniek, 2012, p. 631). Thus, conversations may flow less smoothly than in-person interviews due to the absence of nonverbal cues or prompts that may encourage a participant, such as nodding or smiling (Smith, 2005). Shuy (2002) also argues that the lack of interaction may result in less time to develop rapport with a participant before an interview and a loss of natural conversation, which helps people begin to feel relaxed in an interview. For me, this was very apparent, where natural conversation was extremely brief, and the interview process quickly followed. However, this can also be attributed to me being a novel qualitative researcher. I would also have to argue that some rapport was established through the back and forth email communication that occurred from the time the participants expressed interest up to the interview.

An advantage to using telephone interviews is that it is both cost- and time-effective compared to in-person interviews because no travel is required from both parties (Bolderston, 2012). Additionally, Trier-Bieniek (2012) argues that telephone interviews have the potential for more honest conversations as opposed to in-person interviews because there is a sense of anonymity. In hindsight, the anonymity provided by telephone interviews proved to be even more essential considering recruitment occurred at sites where I could potentially encounter participants because of my involvement at The 519 and from being a Ryerson student. Furthermore, participants may find comfort in being in a setting that is familiar to them (TrierBieniek, 2012), and that they have control over, and thus, being more comfortable to express their opinions (Meho, 2006). Trier-Bieniek (2012) also notes the benefit for parents working or 
staying at home with their children, in that they could participate "at a time in the day most convenient for them, without having to neglect their job or finding someone for childcare" ( $p$. 642). This latter point is especially vital to the study at hand because participants were specifically parents with young children.

\section{Data Analysis and Interpretation}

Coffey \& Atkinson (1996) note that data analysis is typically conducted simultaneously with data collection for qualitative research. Thus, interviews were transcribed and coded almost immed iately after speaking with the participants. This was also done in order to make use of the freshness of the conversation, and create memos that would perhaps be relevant in later reviews of the data.

When taking a phenomenological approach to analyzing data, the written data is primarily read openly without a focus on the research question and letting go of any preconceived notions, in order to gain an understanding of the participant's experiences (Wertz, 2005; Kumar, 2012). "Meaning units", or codes, are used to organize the data for further analysis (Wertz, 2005). Neuman (2004) states that this initial process is a way to condense the large amount of data that can be produced from qualitative research. Codes that became apparent to me after reading the first interview transcript were: (1) early years environments used; (2) selection criteria; (3) locations (e.g., specific streets/cities); (4) LGBTQ-specific statements; and, (5) child-specific statements. New codes became apparent as more data were being collected. For example, after reading the second interview transcript, (6) 'general comments regarding early childhood environments' was added as a code, and (7) 'demographic factors affecting selection' became apparent after reading the third interview. No new codes were developed for the fourth and fifth interview, and thus, a total of seven codes were developed in this first stage of analysis. 
To ensure consistency, I re-read all interviews with the seven codes in mind and made changes accordingly.

Kumar (2012) states that the next step of analysis involves taking the initial codes and organizing them into categories that can be applied to all participants. This helps to take the data from individual experiences to a sense of generality (Wertz, 2005). Organization of the primary codes to broader concepts led to the following categories: early years environments used, demographic factors, selection criteria, and experiences. The category of 'experiences' consists of subcategories including 'the Toronto experience', general experiences, and LGBTQ-specific experiences.

Following the second stage of analysis, the application of relevant theory is important to consider, and may be beneficial in revealing aspects that were not yet evident (Wertz, 2005; Kumar, 2012). From organizing my data even further and in applying Queer Theory, it became clear that LGBTQ specific responses made up an immensely large part of my data, which is rightly so considering the population I was studying and the purpose of my study. It also became evident that I should not separate LGBTQ-specific responses because, for one, it was a theme that ran through almost all the data. Secondly, and perhaps most importantly for me, it is a part of who these participants are in their daily experiences. As a result, the subcategory of LGBTQspecific experiences was dissolved, and more specific themes relevant to Queer Theory were created: 'inclusive experiences' and 'heteronormative experiences'.

As a novel qualitative researcher, I found that it was difficult for me to develop themes that did not follow the structure of my interview questions. After my supervisor advised me to look beyond the topics of my interview questions and to further assess the participants' responses, I continued to work on the organization of my themes. This involved further reflection 
on how to retell the parents' experiences through a phenomenological approach along with aspects of Queer Theory. In going through this reflective process, efforts were made not to misinterpret data and to clearly voice the parents' experiences of this particular phenomena, and to also explore how heteronormativity was playing a role in their responses. The next section outlines the finalized themes used to discuss my findings, and support for each of these themes. 


\section{Findings and Discussion}

I have divided the findings into two major categories, which are 'the selection process' and 'experiences in EYEs'. I have identified themes within each section, which will be discussed in detail through the perspective of five parents and compared to relevant research literature. In 'the selection process', the themes I have identified include: 'availability of EYEs'; 'family support programs versus childcare'; 'external factors', which includes the sub-themes of 'privilege' and 'exploring the G, B and Q in LGBTQ'; and, 'selection criteria', which includes the sub-themes of 'quality and convenience', 'inclusivity: significance and construction,' and 'kindergarten: quality, convenience and inclusivity revisited' (see Table 1). In the category of 'experiences in EYEs', the themes include: 'the Toronto experience'; 'recommendations'; 'experiences of inclusivity'; and, 'concerns and experiences of heteronormativity' with the subtheme of 'challenging heteronormativity and improving experiences for LGBTQ parents' (see Table 2). 
Table 1

The Selection Process

Sub-themes

Themes

Availability of EYEs

Family support

programs versus

childcare

External factors

Privilege

Exploring the G, B

and Q in LGBTQ

Selection criteria

Quality and

Inclusivity:

Kindergarten: Quality,

convenience

Significance and

convenience and

construction

inclusivity revisited 
Table 2

Experiences in EYEs

Sub-themes

Themes

The Toronto experience

Recommendations

Experiences of inclusivity

Concerns and experiences of

Challenging heteronormativity and improving

heteronormativity

experiences of LGBTQ parents

\section{The Selection Process}

Availability of EYEs. It is apparent from the interviews with these parents that there was not one clear option to use for the early years, but rather it is somewhat of an exploratory process, in which parents may use many different types of EYEs. A number of participants also mentioned that the selection process is impacted by long waitlists, and thus, parents were sometimes left with limited options and had to use the service that was available to them at that moment. The issue of Toronto waitlists will be explored more later on.

Parents in the study discussed using: family support programs, which they usually referred to as "drop-ins"; a library program; a parenting program with Toronto Public Health; home-based licensed and unlicensed childcare; Montessori childcare; in-school childcare; and, Ontario Early Years Centres. In the interviews, parents often referred to childcare services as 
“daycares". As previously mentioned, all participants live in Toronto, and were able to find EYEs without having to look beyond the city. Three of the five participants are currently using the same early learning centre affiliated with a Toronto university, with the other two participants using registered childcare services operated at their local schools.

Family support programs versus childcare. Two of the parents discussed in greater detail the decision to use certain EYEs, most notably what they referred to as "drop-in centres" versus “daycares." Ariana, who has an early childhood education background, stated:

There's so many layers to what you're looking for in a daycare as opposed to an early years centre. 'Cause the early years centre, you're more in control of it. Like you go in, you do what you do, and then you leave, based on whatever you need. As opposed to where you're just leaving your child at the daycare.

Ariana went into more detail regarding her process for finding a "drop-in", stating that it is important for her to find a good variety of people who attend in order to find parents to connect with while taking part in the centre. She goes on to mention that she has encountered many nannies who use such services who "kind of just sit and chat and do their own thing," and she is unable to make that connection she can make with other parents.

Similarly, Selena discussed the differences between family support programs and childcare services when looking for an EYE. She argued that interactions with staff in family support programs are "quite minimal," whereas with childcare services, they are "a little bit different because you can actually interview them, and they get to know you and your family." She went on to say that choosing an EYE is less of a process when one is specifically speaking about family support programs as opposed to childcare services:

For drop-in programs, they just run their own agenda, which makes it sound bad, but it's 
not that it's bad, it's just they run that program, so you can go to that program or you can not go to that program [...] they have their toys, they have their story time, and you dropin and you go, and then you leave. They don't ask for feedback, they don't meet you individually, typically, so, you go or you don't go. That's how it is. There is no really sort of choosing.

After gaining this background context on what EYEs this sample used, we began to discuss in more detail the various aspects that play a role in selecting an EYE.

Extemal factors. In developing this study, I thought it would be worthwhile to take a look at intersectionality and how that played a role in LGBTQ parents looking for an EYE. My reasoning for this is rooted in more personal reasons, in that I am of Filipino ethnicity and identify as gay. Additionally, during the development of this study, I was working with a local school board to look at the effects of family support programs targeted for lower socioeconomic neighbourhoods and new immigrant families. Thus, these factors were at the forefront of my mind. Thus, parents were asked to discuss how various demographic factors, if any, played a role in their experiences with EYEs, in addition to their sexual orientation. Since the sample ended up being quite homogenous, it is perhaps not surprising that the responses between participants were quite similar.

Privilege. As previously mentioned, this particular sample was all White, middle-class, with a Masters level education. Hence, most of the parents expressed how their education level and income play a role in finding an EYE. For example, Britney, stated:

I am a white female. I am well-educated. And I do make a good living in my career. So, those things possibly give me the comfort level or confidence in many different 
situations, and in communicating, and just relating to [early childhood] staff or any of the daycare program directors.

Other parents discussed how their income helps them to not only afford childcare, but to go to one that they are satisfied with, which can range from $\$ 1,800$ to $\$ 1,900$ per month. Lana joked that "it's practically a second mortgage."

In hearing these responses, it made me think about the availability of resources for lowincome families. This highlights my desire for wanting to obtain a sample from varying income levels, in order to gain a larger perspective on the issue. According to a member of the South Asian Women's Rights Organization in Scarborough, Ontario, childcare can keep low-income families in a cycle of poverty, with the average annual cost of licensed full-time childcare for one child in downtown Toronto costing \$20,619 (Keenan, 2015). To assist Ontario families with childcare costs, they can apply for a subsidy, with the condition that the child is in a licensed childcare program (Ontario Ministry of Education, 2015). However, the waitlist for childcare subsidy is astounding, with 25,116 subsidies available in Toronto, with over 17,000 children on the waitlist (Dhillon, 2016; Keenan, 2015).

Keenan (2015) writes, "[childcare] keeps the poor impoverished, threatens the middle class with poverty, and even presents a significant burden to those with relatively high incomes. For virtually everyone, it's a struggle." But given that minimum wage jobs in the GTA usually earn an individual an annual salary that is about the cost of childcare service in a year, it is especially a problem for low-income families (Keenan, 2015). This is especially a concern for certain members of the LGBTQ community because Canadian research has shown that gay men have reported lower incomes than heterosexual men (Carpenter, 2008). The situation is worse for bisexual individuals, who have been found to have lower incomes than lesbian and gay 
individuals (Carpenter, 2005). According to Carpenter's $(2005 ; 2008)$ research and the current study's sample, it appears that being a gay, bisexual or queer-headed household adds another dimension in finding an EYE, in comparison to lesbian-headed households.

Exploring the G, B and $Q$ in $L G B T Q$. As the only father in the study, Troye was able to provide a perspective on forming a family through adoption, and how that affected his family when seeking EYEs:

I think that we're maybe at a disadvantage because we formed our family through adoption. And after the adoption, you don't have nine months of pregnancy. So what happens is that, getting on lists for daycares is more difficult, like you're not on these lists for as long as people who have their children biologically. So as parents of an adopted child and that demographic, it was definitely much more difficult. Also, as parents of an adopted child, what happens is that $[\ldots]$ if you have a baby that you give birth to, you get a three-month maternity leave plus a nine-month parental leave. So if the baby doesn't come out of your body, then you just get the nine-month parental leave. So what happens at nine months, not only are you strapped, like you're not on lists for a long time, so you can't really find a daycare, but you have to start daycare at nine months, and there's very few infant programs. So that was definitely a disadvantage.

Clearly, Troye's experience is affected by policies on parental leave and his family composition. Policymakers should take into account families formed through adoption, particularly when families are adopting newborns, in order to make up for the lack of maternal leave with adoptive parents. This is particularly important in places like Toronto, where childcare availability is limited. 
Selena also provided a unique perspective by being married to her husband, and both identifying as bisexual and queer parents, as well as raising their child to be gender-open. Like Troye, she reflected on the nature of her family composition:

My partner and I are both queer, but he's a guy and I am not, so we appear to be a straight couple to most people, and I wonder how that affects things in the early years environment in a sense that, would they make more of an effort or a different kind of effort if we were a same-sex couple? Like would they go out of their way to be inclusive? I know some teachers are like, 'if I have a kid in a particular situation, then I will change this activity so that it's inclusive for them.' Whereas maybe, the daycare teachers don't think that any of the kids have queer parents because we're not visible as queer people, so maybe they don't. On the other hand, maybe the fact that we appear straight, and we're asking for these things, maybe it gives us more leverage because they might think it's not just about us, perhaps. [...] we say on our in-take form that we are queer parents, and we're raising [our child] culturally-queer [...] we put that all out there. But I wonder how that's taken up.

Since research conducted exclusively on the bisexual and queer community is limited, particularly in the field of early childhood studies (Averett et al., 2015; Cloughessy \& Waniganayake, 2014), it is difficult to compare Selena's experience with other bisexual and queer parents. However, it is interesting to note the various advantages that she explores in her response. For example, she is able to identify the benefits of appearing as a heterosexual couple, and she is even able to identify an advantage to being a same-sex couple, which may be connected to the acceptance of the LGBTQ community in Toronto. How the setting of Toronto plays a role for these LGBTQ parents will be explored more shortly. 
Selection criteria. The process of finding an EYE for every parent involves having some sort of selection criteria. Thus, parents were asked what factors they take into consideration when seeking out an EYE.

Quality and convenience. Parents listed various factors that fit under the theme of quality. Examples of common responses include the safety and cleanliness of the facility, how the staff interacts with families, the types of resources available for children, the food that is offered, and how the program is run. Furthermore, parents emphasized the importance of just a feeling of fitting in and being comfortable, which was often affected by many of the factors mentioned. A top contributor to the quality of childcare service is that it is licensed under the Government of Ontario.

Several individual factors in regard to quality were discussed by parents. For example, Britney discussed the importance of reliability, while Lana discussed assessing the ratio of staff to children. Selena stated that the environment should be interesting for her child and her family. Ariana specifically discussed the importance of the environment being fairly populated, and that she considers "word of mouth, which ones are the better ones." As a graduate student of Early Childhood Studies, Ariana also added:

You want to have a good variety of toys and materials to play with. How they run it in terms of do they do a circle time? Do they do a snack time? How well is the circle time run? What other things do they have to offer families?

These findings are supported by Lee (2010), who also found that the quality of relationships between staff and children, as well as recommendations from family and friends, are important considerations for lesbian mothers.

Apart from quality, another theme that arose was convenience. This seemed to be the 
most significant factor for most parents, with convenience covering factors such as location, availability, and cost. Britney, who has two daughters, with one already in elementary school, put the most emphasis on convenience:

We're two full-time working parents, and so, convenience is a huge factor. We would just have poor quality of life if we were travelling all over the place for schools and daycares, and such. So we really lucked out that the convenient options have been actually good options.

The centre that her younger daughter currently uses is both close to their family's home and to their older child's school.

The significance of quality and convenience has been found in past literature that studied heterosexual parents' selection process of EYEs (Galotti \& Tinkelenberg, 2009; GlennApplegate, Pentimonti, \& Justice, 2011). As previously addressed in the research gaps, there is a lack of studies on selection considerations for EYEs among LGBTQ parents; however, it has been found that they are more likely to consider issues of inclusivity (Goldberg \& Smith, 2014), as will be demonstrated in the following section.

Inclusivity: Significance and construction. After parents discussed their selection criteria, I explicitly asked them how important inclusivity of the LGBTQ community in EYEs was to them, to which all parents indicated that it was significant. Although, Selena was the only parent to list diversity first, when providing her list of selection criteria. She specifically stated that it was important that the environment have diverse materials, such as stories and songs that “don't represent just one kind of family, and don't reinforce gender stereotypes." Additionally, it was important for her to find an environment that was comfortable with using they/them pronouns and not gender her child. Britney responded, “if we didn't feel that [staff] were 
inclusive, open-minded, and accepting of the [LGBTQ] community and our family, more specifically, then I wouldn't feel comfortable sending my children there." Lana noted that inclusivity is "very important" to her because she wants her son to "feel that it's okay that he has two moms."

Afterwards, parents were asked how they assessed inclusivity in early EYEs, with several prompts, such as observing the staff, the environment, and philosophies and policies. Britney stated that she takes a look at what books are available, and Troye observes the images on the walls. Selena noted that assessing the environment is the easiest factor when determining inclusivity of an EYE, in comparison to assessing staff and policies.

Selena went on to discuss how evaluating the staff's attitude toward inclusivity is a challenge because staff interaction is "quite minimal" with family support programs. Additionally, with childcare services, it takes awhile to get to know the staff and it depends on family involvement, as well. Furthermore, when interviewing with a childcare service, Selena brought up the point that "you're generally only asking one person, and there's lots of people that come into contact with your child at the daycare." However, parents noted that there is a lot to be learned about the staff's attitudes by listening to the language used in the types of songs they sing, the stories they read, and when they interact with families. Several parents discussed disclosing to staff that they are a same-sex or queer family, which allows parents to assess the staff's comfort level in working with such families. Lana noted:

When I talk to a staff member, I would briefly mention that we're a same-sex couple, and just look at their reaction. I know it may not be the best indicator, but it does help. I certainly crossed out one of the daycares with that.

A few parents also explicitly asked the staff if they have experience or are comfortable with 
LGBTQ families, a finding supported by Lee (2010) in her research with lesbian mothers.

LGBTQ parents disclosing their sexual orientation or family composition has also been cited in the literature as a way of assessing inclusivity in EYEs and challenging heteronormativity (Goldberg, 2014; Lee, 2010; Skattebol \& Ferfolja, 2007). Although I did not delve further into what parents thought about disclosing such information, a colleague of mine noted that it is interesting that LGBTQ parents feel the need to disclose such information, whereas heterosexual parents most likely do not give such information a second thought because heterosexuality acts as the default sexual orientation. Although I could not find research to support this argument in the early childhood field, Chapman, Wardop, Freeman, Zappia, Watkins, and Shields (2012) found that with healthcare services in Australia, participants who did not disclose their sexuality or gender identity were assumed to be heterosexual. This is not surprising given that heteronormativity creates the assumption that everyone is or should be heterosexual, as referenced in the beginning of this paper (Bryan, 2012). Clearly, heteronormativity is playing a vital role in the issue of disclosure in EYEs.

Seeing other same-sex families present in the environment was another indication of an EYE's inclusivity. This factor is especially important to Ariana when using family support programs, where parents have an opportunity to "connect with other parents." Troye shared a similar sentiment, in that it helped seeing other same-sex families present in a centre, but that for him, "it wasn't a deal breaker." Similarly, Lana mentioned, “it kind of makes me happy if I see a rainbow flag on the doors or whatever, just for inclusion, but it's not the priority." This common response of inclusivity not being a top priority is important to take note of in later discussion of these parents residing in the city of Toronto.

When asked about whether or not parents took into consideration a centre's philosophy or 
policy when assessing inclusivity of an EYE, they indicated that it was not a factor they really considered. It was more so about all the other factors discussed, first and foremost, and if there was a "red flag" or an instance in which policy would be beneficial, then that would be the moment for them to take a closer look.

The importance of LGBTQ-friendliness and the presence of other LGBTQ families is supported in the literature (Goldberg \& Smith, 2014). However, the largest discrepancy between the current study and Goldberg and Smith's (2014) study is the ranking of educational philosophy. Educational philosophy was found to be the top priority for Goldberg and Smith's (2014) lesbian, gay, and heterosexual adoptive parents, whereas educational philosophy was not much of a concern for the current sample. This difference may be due to the design of the two studies, with Goldberg and Smith (2014) distributing questionnaire packets with a list of choices for selection factors, rather than using the method of qualitative interviews with open-ended questions. The way in which the previously discussed criteria play a role in choosing a child's elementary school is discussed in the next section.

Kindergarten: Quality, convenience and inclusivity revisited. Since most parents in the study had children who were about to enter kindergarten in the following school year, or who were already attending elementary school, I took this as an opportunity to discuss how looking for a school compared to looking for an EYE. Similar to selecting an EYE, the themes of quality and convenience appeared again. All the parents who had children going to school in the fall or already had children going to school made it clear that being in a specific catchment area predetermines the school that you attend, unless a decision is made to look externally or to relocate.

Ariana discussed how she had two options in her catchment area - a Catholic school, 
which "literally is across the street" or the local public school. Inclusivity played a major factor in Ariana and her family's decision:

In terms of it's population, I mean it being Catholic, would he really be the only boy with two moms, you know? And just the general population. So I just decided to keep him with his public home school, just 'cause I felt like it would be more inclusive for him. Britney echoed this sentiment, stating that she and her partner knew that they wanted their children to go to a public school. She added that she was very satisfied with what she saw in the public school in her catchment area, in terms of the programs run in the school and the available extracurricular activities. She went on to say that she and her partner were not looking for anything specific when looking for a school, but that there were "no red flags" with their local school, and saw many positive aspects. Thus, their catchment area and their family's one condition of attending a public school worked out for them.

School scores seemed to be an essential determinant for quality of a school for these parents. Troye discussed how his family decided to relocate, stating, "we kind of wanted to move anyway, but we ended up moving to another area just because of the scores of the school, it was really incredibly low." School rating was also an important consideration for Lana and her family when they relocated for their own personal reasons. In addition to school scores, Troye also discussed his family's process of looking at school websites, "any language about the schools being inclusive," and looking at the events that the school has scheduled, like Pride events, for instance.

Although Selena's child just turned two-years-old, I decided to go ahead and ask if her family had started looking into schools, in which she noted that their child would be attending the school where their childcare is operated: 
I believe that's the school where the [Toronto District School Board] runs their programs for gender independent kids, like there's an after school program for gender independent kids, and it takes place at that school. I think the school also has gender-neutral bathrooms or uses all-gender bathrooms. So the school itself has had quite a lot of stuff around gender happening.

Cowley and Easton (2015), who authored the most recent report on Ontario's elementary school rankings, state that school scores help parents choose a school. In Ontario, these scores are determined by the level of achievement on standardized test scores (developed by Ontario's Education Quality and Accountability Office) in reading, writing, and mathematics distributed in grades three and six (Cowley \& Easton, 2015). Academic reputation, and local school availability, have also been found to be top considerations for LGBT parents in the States (Kosciw \& Diaz, 2008). Additionally, Kosciw and Diaz (2008) found diversity of the school population to be the third most common response among LGBT parents, similar to responses given by Ariana and Selena. Choosing a school that values diversity has been found to be a significant factor in other research studies with exclusively lesbian families (Gartrell et al., 1999; Mercier \& Harold, 2003).

\section{Experiences with EYEs}

With discussions of the selection process completed, I thought it would be essential to talk about the actual experiences these parents had when they were going through this selection process, and the experiences that occurred when they were a part of an EYE.

The Toronto Experience. As reported previously, the sample for the current study is specific to the metropolitan city of Toronto, Ontario. The lesbian mothers in the study all explicitly stated that being in Toronto did make things easier in terms of being a same-sex family 
and how that affected their experiences with EYEs. Ariana even noted, "people usually seem to be pretty excited about it, when you go and you say '[my child has] two moms'. It's almost a novelty to some people, so they kind of think it's really cool." Ariana, who resides just a block away from The Gay Village, mentioned several times throughout the interview that her experience has been so positive, that she felt her responses may not really target the issues of LGBTQ inclusivity that the study is targeting. Nevertheless, she went on to say that she likes knowing that her son will be going to school where she is "pretty sure he won't be the only one with two moms there." Selena also stated, "I feel like most people are aware, and have had some contact, especially in downtown [Toronto], with same-sex parents, and queer parents, maybe gender independent kids." Additionally, the participants discussed how feelings of inclusivity would definitely differ in other cities outside of Toronto, with Lana specifically stating, "I'm sure small cities, small towns, are a different story."

Given these positive statements, it may explain why several parents did not deem seeing other same-sex families or symbols LGBTQ-inclusion to be a top priority. These statements of positivity are contradictory to Epstein (2012) and Stanley's (2015) findings, in which parents recalled more negative experiences and a lack of inclusion specifically in Toronto EYEs. The current findings also counter findings in another study conducted in an urban region of Sydney, Australia with an LGBTQ enclave (Skattebol \& Ferfolja, 2007). More specifically, Skattebol and Ferfolja's (2007) participants were able to identify many instances of heteronormativity, and go on to argue that educators were not actively seeking out inclusive resources that were readily available to them in the lesbian-friendly community. However, it is important to point out that Skattebol and Ferfolja's (2007) study was conducted almost 10 years ago.

The difference found between the current study and the other Canadian studies by Epstein 
(2012) and Stanley (2015) may also be attributable to limitations in the current study, such as the sample size, which will be discussed later on. Additionally, the differences in the findings may be due to the significant factor of inconsistent policies between EYEs in Ontario, and that the experience depends a lot on the staff's values and training as well, both of which have been highlighted in past literature (Robinson, 2002; Stanley, 2015). Furthermore, Goldberg and Smith (2014) discussed how the social context can influence parents' perceived mistreatment. In this case, however, Toronto and the study being conducted during Pride month may have influenced parents to see more positive aspects than negative.

In contrast to the positives of living in Toronto, parents also noted the primary challenge of being able to find a good centre because of waitlists. For instance, Selena stated, "you pretty much have to take what's offered to you, or risk not having a spot at all." Furthermore, Britney said:

It's difficult to find a centre period. To get a child into daycare. In almost anywhere in Toronto. [...] we kept trying, and trying to get on a waitlist in any centre in Toronto. [...] that would be the biggest struggle, is just getting into a licensed daycare.

Lana's comments support this finding, stating that she had her son on several waitlists while she was pregnant, and she waited almost two years to finally get into a childcare centre, which she finds to be a "ridiculous" wait time. She went on to say that looking for a childcare service was a "horrific experience":

It took me awhile to find more or less organized home daycare website, where all the daycares would be listed there in the area that I lived, and then just calling the daycares, running to see them. All of this could've been eliminated with a little more licensed daycares in Ontario. [...] finding a good centre in general [is a problem, not being 


\section{LGBTQ].}

Lana emphasized the importance of more licensed childcare because she had very minimal options when her maternity leave was over and she needed care for her 12-month old son. She ended up using home-based unlicensed childcare, where she did have a positive experience, but she would have rather been somewhere licensed. She went on to recommend that government regulated daycares need to be expanded, especially because "there are more children being born than the daycares open." Troye's experience was similarly quite challenging, especially when looking for childcare for his daughter, in which he stated "infant spots are far and few between."

This issue of childcare waitlists is documented in various Toronto news outlets along with the issue of cost, as discussed earlier with subsidy waitlists. Furthermore, a Toronto Star article reported that as of October 2015, there are 346,320 children younger than 12 years of age in Toronto, with only 64,700 licensed childcare spots (Keenan, 2015). This problem clearly goes beyond just LGBTQ parents. In addition to the issue of cost and waitlists, this sample spoke about a few other issues regarding EYEs that go beyond experiences of just LGBTQ parents.

Recommendations. In discussing EYEs, parents were able to speak about issues from their social location as a parent, more so than as an LGBTQ individual/parent. For example, Britney noted that she is satisfied with the staff and programs she has encountered, but that she would like to see more books, "whether it's fiction or non-fiction." She also made the suggestion of collaboration between centres:

I think that [collaboration] would actually be something that would be really beneficial to all centres, to be able to learn from each other. It would be good for daycares to be able to connect with one another and learn from one another.

She justified this response by mentioning that she is very happy with the inclusivity at the current 
centre her family uses, and that other centres that may not be as inclusive could learn from what their centre is doing.

The positivity in Britney's comments is interesting to hear in comparison to several of Troye's statements. Troye's interaction with the staff is also important, in which he stated, 'knowing that they're treating you and your family as individuals rather than just treating you as a number was important." Troye noted that he has come across a few centres where "the workers were not involved or interested, or seemed apathetic," which made it an easy decision for his family not to attend those centres. He recommended having better working conditions for staff, in which there is less turnover. He also stated:

If they were paid more, respected more, they'd be more involved, and then, have greater [...] involvement, and good investment in their jobs, and then subsequently, the children and then the types of families they have as well. It's more a systematic issue.

He noted that the lack of involvement and interest of staff was generally towards all families, and not just toward same-sex families. Another issue that he brought up is the celebration of specific events and holidays that are not inclusive, such as Christian holidays and Mother's Day and Father's Day. Again, he stated that EYEs that celebrated such events were easy to cross off the list of potential centres to enroll in or attend. The significance of such inclusive events and holidays from an LGBTQ perspective will be discussed more next.

Experiences of inclusivity. Parents were able to speak about many positive experiences in EYEs in regard to LGBTQ inclusivity. Ariana and Troye, who attend the same centre, discussed how they are very satisfied with how inclusive their centre is in regards to holidays and events like Mother's Day and Father's Day. Both parents specifically expressed the issue that surrounds Mother's Day and Father's Day for LGBTQ parents, with Troye mentioning that it is a 
day his family has to confront every year. Troye also noted the different representations of families on the walls of their current centre.

Ariana mentioned that at another centre she was a part of, a staff member asked her what she would like to do for Father's Day, and that an infant-toddler program did an art activity that said 'Happy Parent Day'. Selena discussed a similar positive experience at her child's centre, where they also celebrate Parent's Day. She explained, "even though my child has a mom and a dad, as a queer parent, I was pleased that $[\ldots]$ they celebrate Parent's Day.”

Britney discussed her positive experiences as well, for instance, when her family used a family support program located in a church basement, stating that the staff and other families were welcoming. I had specifically asked her about her experience with this program given that attending a public school, rather than a Catholic school, was a factor she had discussed earlier on in her interview. She also mentioned that her current childcare centre is very inclusive, which is demonstrated through the various cultures and religions included in their activities and program calendar, with Pride being included. She went on to highlight the importance of such inclusivity, "so that our children get an idea of what other cultures and religions are about, that part of their culture and family structure is also represented, along with a whole many others."

Since the childcare centre Selena's family currently uses is located in a school, she was able to make observations of the school environment, as well. She saw that one classroom door had a Pride flag on it, and another classroom displayed artwork with "rainbow hearts" in the month of June that said who the students love. She noted that she was unsure if there was any explanation around Pride with the activity, but because it was in the month of June, "it seemed very connected to Pride.”

Selena recalled another experience, in which a teacher brought her own culture into the 
class, explaining that this was an occurrence she particularly liked because it "was a bit of a signal that if you feel comfortable bringing in who you are, you're going to let other children bring in who they are, who their families are." She went on to discuss the respect she has felt from past childcare staff, stating, "staff were very interested and in receiving any kind of education that I wanted to bring to them, and they would ask me questions, and were really, really comfortable." On the current childcare staff, she said, "they're really great, and very respectful, and they really listen to me and my partner about the kind of language we want them to use with [our child]."

Selena also recalled one interview with a daycare, in which she asked the Vice-Director, "do you have any books that have representation of different kinds of families?" and the ViceDirector knew exactly where one of the books was located. Selena explained the significance of this by saying, "I was really happy to see that it wasn't like way in the back, covered in dust, or lost. She knew exactly where that book was, and it was in circulation." Other parents also remembered seeing learning materials representing different family structures available in centres they used in the past and are currently using. This a much different experience from the Australian mothers in Skattebol and Ferfolja's (2007) study, who requested or brought in their own resources representing same-sex families, with mothers adding that even if the resources were in the centre, they were not being made readily available. Interestingly, Stanley (2015) conducted a similar study in Toronto, and found that parents did have to bring in their own resources for their families to be represented. This discrepancy may be due to the sample obtained, which will be discussed in greater detail in the limitations section of this paper. Nevertheless, what seems to be the most promising finding from these interviews is that parents were able to talk about how EYEs and schools celebrated Pride and were inclusive to LGBTQ 
parents, and thus, challenged heteronormativity in children's institutions.

Concerns and experiences with heteronormativity. Fortunately, parents' accounts of EYEs did not include instances of conscious heteronormativity, such as outright discrimination against LGBTQ families (Fox, 2007). One reason for this is briefly touched upon by Lana, who states, "most people, I would say, are inclusive. Of course there are still people that are not, and I really don't want to deal with them, but I do want to screen those people out, if I sense that." The literature has found that LGBTQ families are active in seeking out diverse, LGBTQ-friendly spaces in order to reduce such negative experiences (Goldberg \& Smith, 2014; Lee, 2010).

However, Ariana and Selena did express concern about what their children will face when they enter school. As previously discussed, Ariana said that her son is comfortable with having two moms, but she does not know how that will change as he becomes older. Similarly, Selena is concerned about how older children will affect her child's thinking, especially because her child is the youngest in the class. She went on to say, "it adds another layer of complexity around the environment, and that it's not just the staff [my child is] working with, but it's the other children, and maybe also their parents." Past research has found that young children of LGBTQ families are open about their family composition, but older children are not as open (Litovich \& Langhout, 2004). Litovich and Langhout (2004) explain that this may be due to children developing an understanding of heteronormativity. The main concern here for the parents appears to be how conscious heteronormativity may impact their children, as they have been active in reducing such forms of prejudice and discrimination for their families by seeking out LGBTQ-friendly environments.

Another concern Selena shared is when she is not present in the childcare centre, as opposed to when she was able to be present at family support programs. Selena's biggest worry 
here is whether staff continue to use they/them pronouns with her child because there have been instances that her and her partner had to correct the staff. Selena noted that, with pronouns, there is this process of correcting people's usage because it is fairly new to people; however, she adds, with what she has seen with the staff, they are respectful of her family's wishes.

Furthermore, Selena discussed her concerns about addressing issues of inclusivity in the current centre they use. Since her family had recently joined the centre, she does not know what activities or events are done to celebrate Pride. She went on to discuss how she may go about addressing this in the year to come:

Come next June, I'll get to talk to the daycare teachers, and say, "so it's Pride, do you think you could do some exercise about different kinds of families, or could you do something about love, or friendship, and like with rainbows." Like it doesn't have to be very explicit. I mean, really, I would prefer them to be more explicit. [...] I don't know if they will. I'm a bit scared to ask the question 'cause I remember asking the old daycare like, "what kind of stories do you read?" "Oh, mostly we read stories about the letter 'B"" [laughs]. Like that doesn't really have a lot of value necessarily attached to it. I feel like this is a place for values, but [...] I just don't know what they would say about that. But I'm hoping they'll do something. I know they do stuff for different cultural holidays. They do stuff for Rosh Hashanah, [...] Eid, [...] Chinese New Year. So I feel like Pride goes along with that, but, I don't know, I worry a little bit about them saying, 'they're too young."

Selena's concerns about being assertive and active in the inclusion of Pride and the LGBTQ community indicate the prominence of heteronormativity in EYEs. Although she is very open about being a queer family, she expressed concerns about pushing such boundaries for several 
reasons, including what other parents in the environment may think or say. This fear of voicing one's opinion or remaining invisible is not new to LGBTQ parents in EYEs (Robinson, 2002). The fact that policies exist on the matter of discrimination, but parents like Selena are still fearful of what could result in voicing one's thoughts speaks to the dominance of heteronormativity in EYEs (Robinson, 2002).

Selena was also able to speak about several instances of heteronormativity, all of which were encounters with other parents attending the EYEs. This finding is not surprising, since literature has discussed a lack of comfort from other parents to be a challenge for LGBTQ families (Goldberg, 2014). One of Selena's memories is as follows:

[A dad] thought that there was one boy baby, and all the other babies there were girls. And he said something like, "oh, which baby are you going to give a rose to?" Like The Bachelor kind of thing. And that comment, I did not like that comment, I thought that was very problematic on many levels. But that didn't come from the program, that came from the parents.

She recalled another memory, which occurred with a parent that she regards as being "super friendly":

I was saying something about my partner, and she thought I meant business partner [laughter]. So I'm like, "no, my partner, like my husband-partner." [...] But, that, I thought was kind of funny 'cause in my circle [of friends], you know what you mean when you're partnered; you don't automatically think business partner.

Finally, she mentioned an incident that indirectly involved her child:

Another dad at the new daycare was talking about [my child] and gendered [them], and I said, “oh, we're actually raising [them] gender-open, so we're letting them decide their 
own pronouns." [...] So anyway, he kept gendering my child, and that happens a lot. So, I do think it's kind of interesting how other parents-it's not even the interaction with the child per say, but it's the interaction with me, as a queer parent raising a kid gender-open, like how they affect it.

Janmohamed (2010) discussed other examples of heteronormativity in EYEs, such as children being lined up by gender and enrollment forms that families must complete that specifically ask for names of the mother and father of the child. Selena mentioned both examples in her interview, stating that neither have been a problem for her, aside from a vaccination form for Toronto Public Health, which is outside the field of early childhood. But since Selena's experience with the health form, the Ontario government is making changes to their forms to replace the words "mother" and "father" with "parent or guardian" in order to "reflect the diverse nature" of Ontario families (The Canadian Press, 2015).

As demonstrated throughout this section, Selena had plenty of encounters with heteronormativity in EYEs. What I found to be interesting is that she had the most negative experiences to discuss in comparison to the parents in same-sex relationships. As she mentioned earlier on, there are many layers to experiences of bisexual and queer opposite-sex families because, on the surface, they appear as a heterosexual couple. Again, it is difficult to compare Selena's experiences as a bisexual and queer individual due to the lack of research within those specific groups and the topic at hand. Therefore, it is essential to provide her experiences, even if she is the only parent encountering these situations.

Challenging heteronormativity and improving experiences for LGBTQ parents. Despite the lack of negative experiences discussed by all parents, they were able to speak about improvements that could still be made to EYEs in regard to inclusion of LGBTQ families. 
Ariana mentioned how she would like to see more LGBTQ-specific programs, noting that a few existed with a particular centre, a few years ago, that are no longer running. She mentioned that the centre still holds "queer mixers," but she feels, "it's still very hetero-based and not very focused on the queer culture." She added that she and other LGBTQ parents really liked the specific programming, and she is unsure if they will ever find that again. She further elaborated that specific queer programming was positive for her because "you would for sure be amongst the majority of people who are same-sex families," rather than being in the minority, which Ariana argued is often the case in EYEs. She even talked about attending mom groups that she stopped going to "because they're very hetero [...] and talking very much about their husbands." She later discussed the matter with more focus on her child:

It would be nice to have more [...] places where we would go, and we would certainly find family make-ups that are similar to ours. [...] I think more for our kids, too, [...] just so they go and they see other kids that have similar make-ups to their families. May not be so much for us, but for the kids to feel that inclusion, as well. [...] it's just nice to be able to be amongst other families that look like yours. [...] it's still majority hetero out there.

Ariana's latter point about heterosexuals being the majority seems to have less to do with actual numbers, but rather being the 'other' in a very heteronormative society (Surtees \& Gunn, 2010). What is also significant to point out with Ariana's response is the aspect of being surrounded by same-sex families, which does not take into account opposite-sex bisexual and queer families, such as Selena's. Exploring these dynamics within the LGBTQ community may be beneficial in future research with LGBTQ families.

Lana, who currently attends the same childcare centre as Ariana, made a similar point, 
stating, "it would be kind of helpful if the teachers would, maybe not even introduce, but at least let the LGBT parents know that there's another kid in the daycare [...] that also have LGBT family." She said that it would provide a more "home-y" feeling, knowing that "there's a little bit of common background" with another family.

Britney discussed how she would like to have a larger variety of books available in EYEs representing more different family structures. But she went on to say, "that's not a huge thing. I think people who run the program, and the [early childhood educators], have the biggest impact for setting the tone for acceptance and inclusivity."

Selena discussed various areas of improvement in regard to inclusivity, by first stating, “in general, I wouldn't say [EYEs are] inclusive, but they're also not not inclusive." She explained:

Like one of the drop-ins that I went to, when we do Wheels On the Bus, sometimes they go, "the moms on the bus," "the daughters on the bus," "the caregivers on the bus," "the grandmas on the bus." So, they do talk about lots of different people. There's not specific attention to same-sex parents or queer parents. But they do try to have lots of different people on the bus. [...] it would be more of an absence rather than something done negatively.

She goes on to discuss songs that are male-centric, like Farmer Brown, or "Old MacDonald had a farm, e-i-e-i-oh, on his farm he had...," and "the farmer picks a wife." She argued that continued practice of such songs demonstrate an "assumption of heterosexism." She added:

I think it's really important for all the early years centres to do a lot of work against gender stereotypes. And it's connected to the LGBT community because there is this idea out there that boys do certain things, and girls do certain things, and moms do certain 
things, and dads do certain things. And whether you're trans, $[\ldots]$ in a same-sex couple, [...] if you're a single parent, regardless, how we talk about gender, and gender stereotypes, has a connection with the kinds of families that queer kids are in. So, I would like to see more disruption of some of the songs that we sing. So when I sing Old MacDonald Has a Farm, I change Old MacDonald Has a Farm to 'she' [...] just so not every character is 'he'. And I use 'they' a lot for [...] play. And I try not to gender other kids either $[\ldots]$ And so, I'd like to see more of that.

Additionally, Selena mentioned that she approaches EYEs with the assumption that they have work to do towards inclusivity and disrupting heteronormative practices, which is not uncommon for LGBTQ parents (Glass et al., 2015). She recalled one experience in which she felt extreme disappointment because the situation that arose was not something she was expecting from a centre so focused on inclusivity of the LGBTQ community. Her explanation of the incident is as follows:

When I went into [the centre] once, and the signing sheet asks 'what pronouns you use', 'what pronouns your child use,' and I wrote my child uses 'they/them' pronouns, and then the first volunteer, I don't know if it's volunteer or staff, uses gendered pronouns for my child. And my child, I think, was also wearing a name tag that said "my pronouns are they/them." So, that, I was really upset about because I said 'this is why I go to [this centre], my expectations for [this centre] are higher.' My expectations there are that people will spend the time to find out the pronouns and use the pronouns.

Finally, she reflects on the issue of explicitness, and how that plays a role in others not really knowing what it means to be inclusive. She recalled a time when she asked a staff member at her child's current centre a question pertaining to the centre's inclusion practices. She said that 
the staff member replied with a very generic response like, "we're very inclusive, we accept everyone. We celebrate diversity." She elaborated further:

She wasn't really able to give me an example, or it seemed more like she was regurgitating a statement. [...] I didn't get an indication of actually how they put it into practice, [...] like it was good that they were saying they're inclusive, but how? How are you inclusive? Like what do you do that makes it inclusive? Being inclusive is not just not being homophobic. What do you do to make this an environment where different families are celebrated and acknowledged?

She went on to add in the final reflections of our interview:

I would really like daycares to be very explicit about their policy when it comes to inclusivity around queer families, and also multiculturalism. [...] that's something that I feel should just be part of, not just their policy, but also every parent. I don't think [daycares] should wait to be asked, "so, what do you do around this?" Like I think it would be good for each daycare [to say] for any parent that comes on a tour, "oh, and we're very inclusive, so we celebrate different holidays, we also celebrate Pride." Instead of putting the onus on me, as a queer parent, to ask the questions [...] and then they just have to be reactive or responsive to me. I'd love to see the daycares take that responsibility for them to take the initiative. [...] I think part of my fear around wanting to celebrate Pride is I worry about, 'well, what would other parents say?' and if the daycare took that off, and be like, "this is what we do, we celebrate Pride" that would put me much more at ease, as a parent. So, I'd just really like to see the daycare be very explicit in their inclusivity, both in policy and in practice.

Janmohamed (2010) discusses the lack of explicitness in early childhood curriculum and 
practice. She argues that what exists are "superficial attempts to embed notions of diversity and equity and a refusal to acknowledge how significantly different family composition is on the current social and political context" (p. 307). It is essential for early childhood educators to shift their "superficial understanding of diversity to deeper reflective practice" (Janmohamed, 2010, p. $312)$.

Troye's final reflection on the study at hand involved a very insightful perspective on how his family challenged not only heteronormativity, but the norms of society in general:

I think the one thing that we discovered through the past six years is the alliances and the connections with other families that are not two-parent White families, and I think that that's been critical and important in sort of speaking to teachers, and speaking to principals, and speaking to daycare workers, about not only $[\ldots]$ potential problems for us, but how they align with potential problems for others $[\ldots]$ that don't fit into that kind of heteronormative situation.

Troye's response is comparable to Bower and Klecka's (2009) argument that is important to explore the experiences of parents "who exist outside of social constructions of normal" (p. 238). Lesbian mothers, as Bower and Klecka (2009) found, and many other marginalized parents, may feel isolated in their children's educational settings, and a deeper understanding of their perspectives is important towards involvement with educators and the learning environment. Collaboration between families and educators is important to consider when thinking about how this research is significant for future practice and policy.

\section{Strengths, Limitations \& Future Research}

The current study addresses various gaps in the research on EYEs in relation to the LGBTQ community. Firstly, it is an empirical qualitative study, which Averett et al. (2015) note 
is lacking in this specific area of research. Secondly, I intentionally recruited parents of children age 6 and under to target the specific early childhood age group, which has also been lacking in research with LGBTQ parents (Averett et al., 2015).

The current study also demonstrates numerous strengths that can be found in qualitative research (Tracy, 2010). Firstly, the topic is relevant to the issues going on in today's society. News outlets around the world have documented countless stories of LGBTQ individuals being victims of violence, with a very recent and tragic example of this being the Orlando massacre in June 2016. I believe that in order to overcome such occurrences, we as a society must continue to educate those around us; my way of doing that, as a researcher, is by researching the LGBTQ community and giving them a voice. On a more positive note, there was also significant news coverage when the U.S. Supreme Court legalized same-sex marriage in all 50 states in June 2015 (CBC News, 2015). Given this significant achievement in the States that challenges heterosexual norms, the current study's purpose to explore LGBTQ parents' position in EYEs does seem quite worthy of study.

Tracy (2010) also considers sincerity and credibility to be important tenets to qualitative research. I believe I have been transparent in my potential biases and challenges in the research, and have indicated that I am a novel qualitative researcher. I have also tried to use as much of the participants' voices as possible through the use of quotes, or summarizing responses without losing their meaning. As previously mentioned, participants did have the option to review their transcripts to increase credibility of the data analysis and interpretation to follow, but they did not want to participate in the process.

Despite such strengths, there are still several limitations to consider for future directions. Being a novel qualitative researcher definitely played a role in the limitations of the study. For 
example, this affected the types of questions I asked initially, as well as probing questions that could have been developed whilst the interview was occurring. In hindsight, it may have been beneficial to ask more specific questions, for instance, if parents disclose their family composition to early years staff, and if so, how soon do they do so? It may also have been beneficial to ask how the families were formed to have better context of the families. Only Troye indicated that his daughter was adopted, and I was left under the assumption that all the female participants had given birth to their children because they did not mention any other alternatives to how their families were formed, and a few noted being pregnant in their responses. However, whether or not that pregnancy occurred during a past relationship with someone of the oppositesex, or if a donor was used is unclear. I felt that the time commitment to participate was a big factor in recruiting parents, and so, I wanted to ensure that parents were not spending more time on providing family background, but instead, on the central questions of the study.

Various limitations also exist due to the sample used. Unfortunately, my efforts to purposively recruit participants who identified as gay, bisexual, transgender, or queer were not as successful as I had hoped, with the majority of participants being lesbian mothers. As the research shows, lesbian mothers are the most researched sample in regards to LGBTQ families and EYEs (Averett et al, 2015). This may partially be due to lesbian mothers being the first group in the LGBTQ community to gain visibility as parents, and because they do not have as many negative stereotypes being parents compared to gay, bisexual and queer men, who have been portrayed as pedophiles (Epstein, 2012).

I saw the importance of obtaining a purposive sample firsthand, when I was finally able to get a bisexual and queer parent for the study, and the data she provided opened up many new perspectives. This is important to point out for qualitative research because of the concept of 
saturation, which is obtaining data until no new perspectives are being revealed, indicating that data collection can come to an end (Creswell, 2014). With the same-sex parents, I was able to see how their experiences began to overlap with one another and with past literature. With Selena, while there was some overlap with the other parents, she was able to provide the perspective of being a bisexual and queer parent, being in an opposite-sex relationship, and rearing a genderopen child. As seen in the previous sections, she also provided many of the more negative experiences in the study's findings, which many of the same-sex parents had a difficult time recalling. Selena herself openly questioned how her experiences compared to other members of the LGBTQ community. This curiosity may be interpreted as her awareness that while there may be similarities between LGBTQ families, that bisexual and queer parents, particularly heteroappearing families, may have some very different experiences.

While same-sex parents may no longer be as invisible as they once were in EYEs (Epstein, 2012), it appears that issues of inclusion may now be more prevalent for bisexual and queer parents. Thus, future research should continue to find ways to fully represent all members of the LGBTQ community through active recruitment of bisexual and queer parents, as well as transgender parents, who have not been represented in the current study.

Another potential limitation with the sample is that all participants reported being White, achieving the same education level, and being paid in a similar salary bracket. Obtaining participants from a variety of ethnicities, as well as socioeconomic levels may provide a different perspective that is yet to be discovered by the research. Obtaining a larger sample size may also provide a more holistic perspective on the issue at hand (Creswell, 2014).

Furthermore, given that the sample all resided in Toronto, it would be interesting to see how neighbouring cities compare on the topic of inclusivity in EYEs. Although Canada has been 
at the forefront of progression with LGBTQ rights (Epstein, 2012; Rayside, 2014), for me, personally, Toronto has been the most explicit in its acceptance of the LGBTQ community with its own Gay Village located in the downtown core. Being in Toronto is when I feel the safest to be walking around with my partner. Unfortunately, that feeling of acceptance and safety is not quite the same in cities of the GTA where I have lived (Oakville, Mississauga) and currently live (Brampton), which are all located to the west of Toronto. Coincidentally, these cities are home to colleges where many students in the area attend to obtain a degree in Early Childhood Education (ECE). In talking about this study with my peers in ECE programs, we have speculated that the current findings would not be the same in cities like Mississauga and Brampton. In fact, we did not even know any LGBTQ parents in the surrounding areas. So, from a personal standpoint as well as from a researcher's perspective, studying this topic in the surrounding cities of Toronto would be of interest, along with more rural locations.

Finally, the sample was also limited to perspectives of the parents, and thus, there was no triangulation of the data from other informants, such as educators and children (Goldberg, 2014; Maxwell, 2009). Including additional perspectives would have added more richness and depth to the current findings (Patton, 2002). I would have liked to include the perspective of the educators in the current study, but given the time allotted to complete this project, looking at one group of informants seemed the most feasible.

Recruiting from marginalized communities. A challenge often cited with recruiting LGBTQ individuals is publicly identifying as such, which can result in stigma and discrimination (Meyer \& Wilson, 2009). I questioned how applicable this is to the current study with the assumption that LGBTQ parents are 'out' to a large extent because, for some, they have been in long-term same-sex relationships and have started a family. However, this allowed me to reflect 
on the fact that I did not have any single-parent participants, and it may be more so those individuals who do not publicly identify as part of the LGBTQ community, especially with the negative stereotypes that surround gay, bisexual, and queer men (Epstein, 2012). Sexual minorities may also reject dominant sexual identity categories (Savin-Williams, 2001). Additionally, McCormack (2014) discusses that it can be challenging to reach LGBTQ individuals who are not part of support networks or LGBTQ communities because they only feel comfortable talking to particular people. Recruiting bisexual individuals specifically is even more difficult because they are a marginalized group within an already-marginalized group (Hartman, 2011). Bisexuality, as well as the transgender community, have been discriminated against in both gay and straight communities (Weiss, 2011). With these latter two points in mind, it supports my decision to highlight Selena's experiences, even if other parents could not relate, in order to provide a more detailed perspective of the LGBTQ experience as opposed to just experiences of same-sex parents.

In order to obtain a sufficient sample of bisexual individuals, McCormack and his team publicly recruited in dense public places (McCormack, 2014). Thus, people who approached McCormack and his team of researchers were publicly out, and seeing the researchers in person negated any fears that potential participants may have in speaking to researchers (McCormack, 2014). Using this sampling approach may prove beneficial in future research on the LGBTQ community.

In regard to recruiting marginalized groups, in general, Rasmussen, Poulsen, Rytter, Kristiansen, and Bak (2016) found various reasons for a lack of participation. Marginalized groups generally had a sense of distrust in research, particularly it connection with the government. There is also the issue of language barriers, especially when recruiting from 
communities with many different nationalities. Time and money may be additional factors, particularly for individuals with low-wage jobs or who work various jobs. Given Rasmussen et al.'s (2016) findings, it comes as less of a surprise that I was unable to obtain racialized members of the LGBTQ community as well as those from lower socioeconomic neighbourhoods. Similar to bisexuality, these are marginalized groups within already-marginalized groups.

\section{Implications for Future Practice and Policy}

\section{Collaboration}

Troye's response about LGBTQ families working together with other non-normative, non-White families encompasses the bigger picture of marginalized communities as a whole, and how they must work together to break down social norms. This can be compared to Britney's more specific reflection of centres collaborating to learn from each other. This concept of collaboration can extend much further than just between families or between centres, as discussed in past literature. In order to disrupt dominant ideologies, such as heteronormativity, parents must work together with early years staff and administration, and the government (Bower \& Klecka, 2009; Stanley, 2015).

While the explicit issue of training educators was not explicitly discussed in terms of LGBTQ inclusion as it was in the literature, collaboration with LGBTQ families towards better teaching practices can be interpreted as a form of training and learning. Evidence of such learning is demonstrated when Selena speaks about reminding staff to use non-gender pronouns when speaking to or about her child, and when a staff member asked Ariana what her family would prefer to do on Father's Day. 


\section{Tokenistic Representation}

While the parents in this study have provided many positive aspects of the topic at hand, it is interesting to note that when discussing resources being inclusive of the LGBTQ community, the resources do exist, but seem to be very few. For example, a few parents recall instances in which an EYE had $a$ book that discussed a same-sex family rather than several books. Similarly, parents discussed seeing $a$ same-sex family present at a few centres they took a look at, rather than finding a large number of LGBTQ families. As Ariana noted, EYEs are still very much used most prominently by heterosexual parents, and that LGBTQ parents usually use EYEs in areas where there is a large population of LGBTQ families, such as The 519, and that is where they often become the majority. As the research notes, The 519 is a well-known resource for the LGBTQ community (Stanley, 2015), and many parents in this study did mention that they used The 519's FRC.

The celebration of Pride is also important to discuss at this point. Since this study was taking place around the time of Pride month in Toronto, parents were easily able to recall how their EYEs addressed Pride. While parents did say that they felt included because their centres were doing Pride activities, it would be interesting to see how these environments continued to support and represent LGBTQ families other times of the year. Several parents were able to speak about this in that their EYEs did not celebrate days like Mother's Day and Father's Day, and instead celebrated Parent's Day.

The issues discussed here relate back to the point of representation in a tokenistic manner (Janmohamed \& Campbell, 2009; Skattebol \& Ferfolja, 2007). To avoid tokenistic representation, educators must actively include resources and activities for all types of people and families, even if those groups are not present or visible in the environment (Glass et al., 
2015). Additionally, educators must continue to be able to support LGBTQ families outside of specific moments in time, like Pride and Mother's Day and Father's Day (Janmohamed \& Campbell, 2009). Perhaps if all EYEs had a fair share of inclusive books and learning materials and are able to be inclusive of LGBTQ families year-round, then LGBTQ parents may be more dispersed throughout various EYEs in Toronto and the GTA. By being prepared with such resources and activities before these families even enter the environment demonstrates genuine support of inclusivity, and will provide that welcoming and comforting atmosphere that parents seek when looking for an EYE. Furthermore, to refer back to one of Selena's statements, prior preparation takes the burden off families to ask about inclusion practices, such as Pride activities. Active inclusion may also be beneficial for EYEs in smaller cities or more rural areas, where the LGBTQ population usually do not feel as welcomed (Goldberg \& Smith, 2014). 


\section{Conclusions}

This study provides a number of essential contributions. Firstly, it contributes to the growing literature on the LGBTQ community in relation to the early childhood field, particularly in a Canadian context. Additionally, the current findings make a distinction between the different groups that exist within the LGBTQ community. What this means is that I was able to discuss perspectives of a bisexual parent in comparison to experiences of a gay or lesbian parent as opposed to studies with the LGBTQ community that often present their findings in a much broader sense and lose the specificity of essential differences, such as experiences of bisexuality (McCormack, 2014). Finally, this study includes positive experiences that are often not found in the literature. The positive experiences retold by these parents demonstrate what is currently working in EYEs and can be used to further build on inclusion practices.

As a member of the LGBTQ community myself, it has been heart-warming to hear how the progression in Canada towards the LGBTQ community has spread into the area of early childhood to be inclusive of LGBTQ families. Nevertheless, the parents in this study do acknowledge that heteronormativity does still exist, but that they have found ways to to disrupt such practices. The EYEs they have used and are using are also doing their job in being inclusive and challenging heteronormativity. To continue to break down such dominant ideologies, more work needs to be done around families who identify as bisexual, transgender, and queer, and for parents who are raising their children as gender-open. Future research should also explore how such progress and acceptance in Toronto can reach surrounding cities and rural areas that are not as LGBTQ-oriented. 
Appendices

Appendix A. Recruitment Flyer

\title{
RYERSONUNIVERSITY
}

SCHOOL OF EARLY CHILDHOOD STUDIES

FACULTY OF COMMUNITY SERVICES

\section{PARTICIPANTS NEEDED FOR \\ RESEARCH: LGBTQ* PARENTS" \\ EXPERIENCES IN EARLY YEARS \\ ENVIRONMENTS}

\author{
Are you: \\ - 18 years of age or older?
}

- Identify as part of the LGBTQ+ community?

- A parent/guardian of a 0 to 6 -year-old child, who looked for an early

years environment in the past year?

If you answered yes to the above questions, you are invited to volunteer in this study to discuss the factors LGBTQ+ parents consider when looking for an early years environment for their child, and their experiences in early years environments.

You will be asked to provide some demographic information about yourself and answer questions in a one-on-one interview.

Your participation will involve one session that is expected to take a maximum of 60 minutes.

If you are interested in participating in this study or for more information, please contact Michael Butac at mbutac@ryerson.ca. Michael Butac is a current graduate student from the School of Early Childhood Studies at Ryerson University, conducting this study as part of a major research project.

The project is supervised by Dr. Rachel Berman, a faculty member of the School of Early Childhood Studies at Ryerson University. Dr. Berman can be contacted at rcberman@ryerson.ca or 416-979-5000 x.7695 


\section{Appendix B. Interview Questions}

1. Could you tell me about what kind of early years program(s) your family has participated in? (e.g. childcare, family resource program/drop in, Ontario Early Years Centre/drop in)?

2. What factors do you take into consideration when looking for an early years environment for your child?

3. How important is it to you for an early years environment to be inclusive of the LGBTQ+ community?

4. What helps you determine this? For example, do you look for acceptance of the LGBTQ+ community in:

a) the staff (e.g. welcoming and inclusive atmosphere)?

b) the environment (e.g. posters, pictures, books and language used in the space, etc.)?

c) what about at the centre or school level (e.g. program philosophy, policies)?

5. How would you describe the process of looking for and finding an early years environment that is a good fit for your child and family?

Prompt if needed--For example, positive experiences? Or negative experiences?

(Are there any positive or negative instances that stand out to you in being a part of an early years environment?)

Thinking about your negative experiences, what do you think could have been done differently?

6. Do you think other demographic factors play a role into your experiences with early years centres, in addition to sexual orientation? For example, your ethnicity, education, income, family composition, etc.

7. Do you have any general suggestions or comments in regards to early years environments in relation to the LGBTQ+ community?

8. Do you have any final words or takeaway messages in regard to the study at hand, anything we haven't touched on that you think is important? 


\title{
Appendix C. Consent Form
}

\section{RYERSONUNIVERSITY}

\author{
SCHOOL OF EARLY CHILDHOOD STUDIES \\ FACULTY OF COMMUNITY SERVICES
}

\section{Consent Agreement}

You are being invited to participate in a research study. Please read this consent form so that you understand what your participation will involve. Before you consent to participate, please ask any questions to be sure you understand what your participation will involve.

\section{STUDY TITLE: $L G B T Q+$ parents' experiences in early years environments}

INVESTIGATORS: This research study is being conducted by Michael Butac, a graduate student from the School of Early Childhood Studies at Ryerson University, and supervised by Dr. Rachel Berman, from the School of Early Childhood Studies at Ryerson University.

PURPOSE OF THE STUDY: This study aims to look at the experiences that LGBTQ+ parents have gone through in seeking an early years environment (e.g., early years centre, family resource centre) for their child, as well as their experiences being a part of an early years environment. Six participants are being recruited for this study. Participants must be 18 years of age or older, identify as part of the LGBTQ+ community, and be the parent/guardian of a child between the age of 0 and 6 . Participants must have sought out an early years environment in the last 6 years. Participants are not required to be currently attending an early years environment. The results of the study will contribute to a major research project (MRP) that is a part of Michael Butac's M.A. program in Early Childhood Studies. The findings may also be used for a presentation at The 519 Community Centre, with permission of the participants and The 519 staff. Additionally, the findings may be used for journal publication.

WHAT PARTICIPATION MEANS: If you volunteer to participate in this study, you will be asked to do the following:

Fill out a brief demographic information form, asking your sexual orientation, family composition, child's age, your age, ethnicity, highest level of education, and annual income. You may skip any questions you do not want to answer.

Participate in one 25-45 minute interview at a mutually agreed upon location. Examples of the type of interview questions include:

- What factors do you take into consideration when looking for an early years environment for your child?

- Can you speak about any positive experiences you have had in looking for or in being a part of an early years environment?

- Can you speak about any negative experiences you have had in looking for or in being a part of an early years environment? 
If you choose, you may review your transcript of the interview, which will be provided to you via email about one week after the interview. This will give you the opportunity to remove any sections of the interview that you do not want included and provide any other feedback on the transcript.

At the conclusion of this project, research findings will be made available to participants in a final report, and with the permission of the participants and The 519, via a presentation at The 519 Community Centre.

POTENTIAL BENEFITS: This study is an opportunity for you to voice your experiences in seeking an early years environment for your child, and your suggestions, if any, to help improve inclusion of the LGBTQ+ community in early years environments. I cannot guarantee, however, that you will receive any benefits from participating in this study.

POTENTIAL RISKS TO YOU AS A PARTICIPANT: The potential risks to you in this study are very low, but because of the nature of the questions asked, you may reflect on unpleasant memories while responding to interview questions. If you begin to feel uncomfortable, you may skip answering a question or stop participation, either temporarily or permanently. Although every effort will be made to ensure confidentiality, there is a very small risk that you may be identified through the personal details disclosed during the interview process. Thus, you may feel exposed or fear a loss of privacy when disclosing your stories. However, I hold no judgment towards your responses and no specific identifiers will be used in the writing of the report e.g., names, centres, schools.

If you attend The 519's Family Resource Centre (FRC), you may not want to discuss negative occurrences in the centre with me, since I am a volunteer there. Similarly, if you attend Ryerson University's Early Learning Centre (ELC), you may not want to discuss negative occurrences in the centre with me, since I am a Ryerson student. Additionally, as an attendee of the FRC/ELC, you may not want to talk about negative experiences at the centre due to the risk of exclusion, if your identity is revealed. Again, every effort will be made to ensure confidentiality. Furthermore, this study is in no way connected to how the FRC/ELC is currently run and the FRC/ELC do not have any access to the data, nor are they funding the project. The project is only connected to these centres in that I have permission to recruit parents/guardians who visit the site.

CONFIDENTIALITY: Audio data will be recorded on a password protected mobile device, and then transferred onto a personal password protected laptop. Once the audio is transferred to the laptop, it will be erased from the mobile device. All electronic data will be stored on a password protected laptop, in a password protected folder. All physical forms will be stored in a secure home office space. Signed consent forms with your name and email address will be stored in a separate folder from your demographic information form. Only the researcher will have access to the recordings and the data.

Following completion of the research study, the data will be kept for five years and then destroyed. Participant numbers will be used on all data collected, and pseudonyms will be used in the writing of the MRP and in any presentation of the MRP. As is required by Ontario law, we must report to the authorities any information regarding child abuse that is disclosed.

INCENTIVES FOR PARTICIPATION: You will not be paid to participate in this study. 
VOLUNTARY PARTICIPATION AND WITHDRAWAL: Participation in this study is completely voluntary. You can choose whether to be in this study or not. If any question makes you uncomfortable, you can skip that question. You may stop participating at any time. If you choose to stop participating, you may also choose to not have your data included in the study. Your choice of whether or not to participate will not influence your future relations with the The 519 Family Resource Centre, Ryerson University, the investigator, Michael Butac, or the supervisor, Dr. Berman.

QUESTIONS ABOUT THE STUDY: If you have any questions about the research now, please ask. If you have questions later about the research, you may contact Michael Butac at mbutac@ ryerson.ca, or Dr. Rachel Berman at rcberman@ryerson.ca or at 416-979-5000x.7695

This study has been reviewed by the Ryerson University Research Ethics Board. If you have questions regarding your rights as a participant in this study, please contact:

Research Ethics Board

c/o Office of the Vice President, Research and Innovation

Ryerson University

350 Victoria Street

Toronto, ON M5B 2K3

416-979-5042

rebchair@ryerson.ca 


\section{Project title: $L G B T Q+$ parents' experiences in early years environments \\ CONFIRMATION OF AGREEMENT:}

Your signature below indicates that you have read the information in this agreement and have had a chance to ask any questions you have about the study. Your signature also indicates that you agree to participate in the study and have been told that you can change your mind and withdraw your consent to participate at any time. You have been given a copy of this agreement. You have been told that by signing this consent agreement you are not giving up any of your legal rights.

Name of Participant (please print)

Signature of Participant

Date

I agree to be audio-recorded for the purposes of this study. I understand how these recordings will be stored and destroyed.

I would like to review a transcript of my interview before data analysis occurs for the project. I would like a copy of the research findings upon completion of the project.

Email address to send transcript/findings

Date

I agree to have my anonymized data included in a presentation at The 519 Community Centre.

Signature of Participant

Date

Thank you!

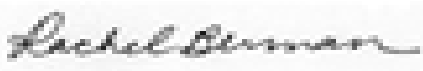

Signature of Principal Investigator

Signature of Supervisor 
1. Sexual orientation:

Sexual orientation:

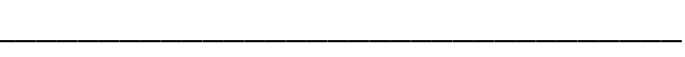

2. Age range:
$\square 18-29$
$30-39$
$40-49$
$50-59$
$60-69$
$70+$

Prefer not to disclose

3. Age of child(ren):

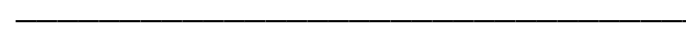

4. Ethnicity:

White

Hispanic/Latino

Black/African American

Native American

Asian/Pacific Islander

Aboriginal

Other:

Prefer not to disclose
5. Highest level of education:

No school completion

Elementary school diploma

High school diploma

Vocational training

College diploma

Bachelor's degree

Master's degree

Postdoctorate degree

Other:

Prefer not to disclose

6. Annual income:

Less than $\$ 24,999$

$\$ 25,000$ - $\$ 49,999$

$\$ 50,000$ - $\$ 74,999$

$\$ 75,000$ - $\$ 99,999$

More than $\$ 100,000$

Prefer not to disclose

7. Family composition: 


\section{References}

Averett, P., Hegde, A., \& Smith, J. (2015). Lesbian and gay parents in early childhood settings: A systematic review of the existing research literature. Journal of Early Childhood Research, 1-13. doi: 10.1177/1476718X15570959

Bolderston, A. (2012). Conducting a research interview. Journal of Medical Imaging and Radiation Sciences, 43, 66-76. doi: 10.1016/j.jmir.2011.12.002

Bower, L. A., \& Klecka, C. L. (2009). Lesbian mothers' bids for normalcy in their children's schools. The Educational Forum, 73, 230-239.

Butler, J. (1990). Gender trouble: Feminism and the subversion of identity. New York: Routledge.

Bryan, J. (2012). From the dress-up corner to the senior prom: Navigating gender and sexuality diversity in PreK-12 schools. Lanham, MD: Rowman \& Littlefield Publishers, Inc.

Campbell, M. (2016, March 31). Greater Toronto Area (GTA) cities and towns. Retrieved July 6, 2016 from http//toronto.about.com/od/communitieslivingspace/a/gta_cities.htm

Canadian Human Rights Act. (1985). Minister of Justice. Retrieved from http:/lawslois.justice.gc.ca/PDF/H-6.pdf

Carpenter, C. S. (2005). Self-reported sexual orientation and earnings: Evidence from California. Industrial Relations \& Labor, 58(2), 258-273. doi: 10.1177/001979390505800205

Carpenter, C. S. (2008). Sexual orientation, work, and income in Canada. Canadian Journal of Economics, 41(4), 1239-1261.doi: 10.1111/j.1540-5982.2008.00502.x

Casper, V., \& Schultz, S. (1999). Gay parents/straight schools: Building communication and trust. New York, NY: Teachers College Press. 
CBC News. (2015, June 26). U.S. Supreme Court legalizes same-sex marriage in all 50 states. Retrieved from http $/ / w w w . c b c . c a$

Chapman, R., Wardop, J., Freeman, P., Zappia, T., Watkins, R., \& Shields, L. (2012). A descriptive study of the experiences of lesbian, gay and transgender parents accessing health services for their children. Journal of Clinical Nursing, 21(7-8), 1128-1135. doi: 10.1111/j.1365-2702.2011.03939.x

Christensen, P. H. (2004). Children's participation in ethnographic research: Issues of power and representation. Children \& Society, 18, 165-176. doi: 10.1002/CHI.823

Cloughessy, K., \& Waniganayake, M. (2014). Early childhood educators working with children who have lesbian, gay, bisexual and transgender parents: What does the literature tell us? Early Child Development and Care, 184(8), 1267-1280. doi: 10.1080/03004430.2013. 862529

Coffey, A. \& Atkinson, P. (1996). Making sense of qualitative data: Complementary research strategies. Thousand Oaks, CA: Sage Publications.

Collingridge, D. S., \& Gantt, E. E. (2008). The quality of qualitative research. American Journal of Medical Quality, 23(5), 389-395. doi: 10.1177/1062860608320646

Cowley, P., \& Easton, S. (2015). Report card on Ontario's elementary schools 2015. Ontario: Fraser Institute.

Creswell, J. (2014). Research design: Qualitative, quantitative, and mixed method approaches. Thousand Oaks: Sage Publications Inc.

De Vaus, D. A. (1991). Surveys in Social Research (3rd ed.). London, UK: University College London Press.

Dhillon, A. (2016, March 1). A look at Toronto's childcare needs. Torontoist. Retrieved from 
http://torontoist.com/

Donalto, A. (Oct 18, 2015). "Transgender Canadians Speak out on Federal Election Issues". The Huffington Post. Retrieved: http//www.huffingtonpost.ca/2015/10/18/trans gender- is suescanada-election_n_8323144.html.

Epstein, R. (2012). Queer parenting in Canada: Looking backward, looking forward. LES Online, 4(1), 13-19.

Epstein, R., Duggan, S., \& Veldhoven, C. (2006). Gay/bi/queer fathers: Entitlement, visibility, pride. Father Involvement Research Alliance e-bulletin, 1(3).

Fox, R. K. (2007). One of the hidden diversities in schools: Families with parents who are lesbian or gay. Childhood Education, 83(5), 277-281. doi: 10.1080/00094056.2007. 10522932

Galotti, K. M., \& Tinkelenberg, C. E. (2009). Real-life decision making: Parents choosing a firstgrade placement. American Journal of Psychology, 122, 455-468.

Gartrell, N., Banks, A., Reed, N., Hamilton, J., Reed, N., Bishop, H., et al. (1999). The National Lesbian Family Study: 2. Interviews with mothers of toddlers. American Journal of Orthopsychiatry, 69, 362-369. doi: 10.1037/h0080410

Glass, V. Q., Willox, L., Barrow., K. M., \& Jones, S. (2015). Struggling to move beyond acknowledgement: Celebrating gay and lesbian families in preschool environments. Journal of GLBT Family Studies, 1-25. doi: 10.1080.1550428X.2015.1039685

Glenn-Applegate, K., Pentimonti, J., \& Justice, L. M. (2011). Parents' selection factors when choosing preschool programs for their children with disabilities. Child Youth Care Forum, 40, 211-231. doi: 10.1007/s10566-010-9134-2 
Goldberg, A. E. (2014) Lesbian, gay, and heterosexual adoptive parents' experiences in preschool environments. Early Childhood Research Quarterly, 29, 669-681. doi: 10.1016/j.ecresq.2014.07.008

Goldberg, A. E., \& Smith, J. Z. (2014). Preschool selection considerations and experiences of school mistreatment among lesbian, gay, and heterosexual adoptive parents. Early Childhood Research Quarterly, 29, 64-75. doi: 10.1016/j.ecresq.2013.09.006

Gunn, A., \& Surtees, N. (2009). We're a family: How lesbians and gay men are creating and maintaining family in New Zealand. Wellington, New Zealand: Families Commission Blue Skies.

Hartman, J. E. (2011). Finding a needle in a haystack: Methods for sampling in the bisexual community. Journal of Bisexuality, 11, 64-74.

Janmohamed, Z. \& Campbell, R. (2009). Building Bridges: Queer families in early childhood education. Toronto: Ontario Coalition for Better Child Care.

Keenan, E. (2015, October 11). From costs to waiting lists, Toronto's child-care numbers are alarming. The Toronto Star. Retrieved from https://www.thestar.com

Kintner-Duffy, V. L., Vardell, R., Lower, J. K., \& Cassidy, D. J. (2012). "The changers and the changed": Preparing early childhood teachers to work with lesbian, gay, bisexual, and transgender families. Journal of Early Childhood Teacher Education, 33(3), 208-223. doi: $10.1080 / 10901027.2012 .705806$

Kosciw, J. G., \& Diaz, E. M. (2008). Involved, invisible, ignored: The experiences of lesbian, gay, bisexual, and transgender parents and their children in our nation's $K$-12schools. New York, NY: Gay, Lesbian, Straight Education Network. Retrieved from www.glsen.org/cgi-bin/iowa/all/news/record/2271.html 
Lee, D. (2010). Gay mothers and early childhood education: Standing tall. Australasian Journal of Early Childhood, 35(1), 16-23.

Litovich, M. L., \& Langhout, R. D. (2004). Framing heterosexism in lesbian families: A preliminary examination of resilient coping. Journal of Community and Applied Social Psychology, 14, 411-435.

Magrini, J. (2012). Phenomenology for educators: Max van Manen and "Human Science" research. Philosophy Scholarship, 32, 1-7. Retrieved from http://dc.cod.edu/ philosophypub/32

Maxwell, J. (2009). Designing a qualitative study. In D. J. Rogg \& L. Bickman (Eds.) The Sage handbook of applied social research (pp. 214-252). Thousand Oaks, CA: Sage.

McCormack, M. (2014). Innovative sampling and participant recruitment in sexuality research. Journal of Social and Personal Relationships, 31(4), 475-481. doi: $10.1177 / 0265407514522889$

Meho, L. I. (2006). E-mail interviewing in qualitative research: A methodological discussion. Journal of the American Society for Information Science and Technology, 57(10), 12841295.

Mercier, L. R., \& Harold, R. D. (2003). At the interface: Lesbian-parent families and their children's schools. Children \& Schools, 25, 35-47. doi: 10.1093/cs/25.1.35

Meyer, I. H., \& Wilson, P. A. (2009). Sampling lesbian, gay, and bisexual populations. Journal of Counseling Psychology, 56(1), 23-31. doi: 10.1037/a0014587

Neuman, W. L. (2004). Chapter 13: Analys is of qualitative data. In Basics of social research: Qualitative and quantitative approaches (pp. 318-334). New York: Pearson. 
Ontario Human Rights Code. (1962). Government of Ontario. Retrieved from https://www.ontario.ca/laws/s tatute/90h19

Ontario Ministry of Education. (n.d.). Child and Family Programs. Retrieved from http//www. edu.gov.on.ca/childcare/FamilyPrograms.html

Ontario Ministry of Education. (2014a). Excerpts from “ELECT”: Foundational knowledge from the 2007 publication of Early Learning for Every Child Today: A framework for Ontario early childhood settings. Toronto: Ontario Ministry of Education. Retrieved from http://www.edu.gov.on.ca/childcare/ExcerptsFromELECT.pdf

Ontario Ministry of Education (2014b). How does learning happen? Ontario's pedagogy for the early years. Toronto: Ontario Ministry of Education. Retrieved from http://www.edu.gov.on.ca/childcare/HowLearningHappens.pdf

Ontario Ministry of Education. (2015, February 12). Financial Support for Child Care. Retrieved from https://www.ontario.ca/page/child-care-subsidies

Patton, M. (2002). Qualitative evaluation and research methods. Newbury Park, CA: Sage.

Pohan, C., \& Bailey, N. (1998). Including gays in multicultural education. Education Digest, 63 (5), 52-56.

Rainbow Health Ontario. (2016). Media reference guide - Discussing trans and gender-diverse people. Retrieved from http://www.rainbowhealthontario.ca/wpcontent/uploads/2016/01/Media-Reference-Guide-Trans-and-Gender-DiversePeople1.pdf

Rasmussen, M., Poulsen, E. K., Rytter, A. S., Kristiansen, T. M., Back, C. K. (2016). Experiences with recruitment of marginalized groups in a Danish health promotion program: A document evaluation study. PLoS One, 11(6), e0158079. doi: 
10.1371/journal.pone.0158079

Ray, V., \& Gregory, R. (2001). School experiences of the children of gay and lesbian parents. Family Matters, 59, 29-34.

Rayside, D. (2014). The inadequate recognition of sexual diversity by Canadian schools: LGBT advocacy and its impact. Journal of Canadian Studies, 48(1), 190-225.

Re:searching for LGBTQ Health. (n.d.). Collaboration. Retrieved June 21, 2016, from http://lgbtqhealth.ca/collaboration/

Riggs, D. W., \& Augoustinos, M. (2007). Learning difference: Representations of diversity in storybooks for children of gay and lesbian parents. Journal of GLBT Family Studies, 3(23), 24-30.

Robinson, K. (2002). Making the invisible visible: Gay and lesbian issues in early childhood education. Contemporary Issues in Early Childhood, 3(3), 415-435.

Robinson, K. H. (2005). 'Queerying' gender: Heteronormativity in early childhood education. Australian Journal of Early Childhood, 30(2), 19-28.

Robinson, K. H., \& Ferfolja, T. (2001). "What are we going this for?" Dealing with lesbian and gay issues in teacher education. British Journal of Sociology of Education, 22, 121-133. doi: $10.1080 / 01425690020030828$

Ryan, D. \& Martin, A. (2000). Lesbian, gay, bisexual, and transgender parents in the school system. School Psychology Review, 29, 207-216.

Ryerson University. (n.d.). About the ELC - Early Childhood Studies. Retrieved July 6, 2016 from http://www.ryerson.ca/ecs/researchlabs/elc/about/index.html

Savin-Williams, R. C. (2001). A critique of research on sexual-minority youths. Journal of Adolescence, 24, 5-13. 
Sherbourne Health Centre (n.d.). About us. Retrieved July 6, 2016, from http://lgbtqpn.ca/aboutus/

Shuy, R. W. (2002). In-person versus telephone interviewing. In J. F. Gubrium \& J. A. Holstein (Eds.) Handbook of interview (pp. 537-555). Thousand Oaks, CA: Sage.

Skattebol, J., \& Ferfolja, T. (2007). Voices from an enclave: Lesbian mothers' experiences of child care. Australian Journal of Early Childhood, 32(1), 10-18.

Smith, E. M. (2005). Telephone interviewing in healthcare research: A summary of the evidence. Nursing Research, 15, 32-41.

Smolkin, L. B., \& Young, C. A. (2011). Missing mirrors, missing windows: Children's literature textbooks and LGBT topics. Language Arts, 88(3), 217-225.

Stanley, A. (2015). The landscape of LGBTQ2S inclusivity in children's services. Toronto: Children's Services.

Surtees, N., \& Gunn, A. C. (2010). (Re)marking heteronormativity: Resisting practices in early childhood education contexts. Australasian Journal of Early Childhood, 35(1), 42-47.

Szalacha, L. A. (2004). Educating teachers on LGBTQ issues: A review of research and program evaluations. Journal for Gay and Lesbian Issues in Education, 1(4), 67-79.

Taylor, A., \& Blaise, M. (2007). Editorial: IJEIEC special queer issue. International Journal of Equity and Innovation in Early Childhood, 5(2), 1-4.

The 519. (n.d.). Retrieved July 6, 2016 from http://www.the519.org/

The Canadian Press. (2015, September 24). Ontario MPPs approve motion to remove words mother, father from government forms. Retrieved from http//www.cbc.ca/news/canada/ toronto/ontario- mpps-approve- motion-to-remo ve-words- mother-father-from-governmentforms-1.3241962 
Tracy, S. J. (2010). Qualitative quality: Eight "big-tent" criteria for excellent qualitative research. Qualitative Inquiry, 16(10), 837-851. doi: 10.1177/1077800410383121

Trier-Bieniek, A. (2012). Framing the telephone interview as a participant-centred tool for qualitative research: A methodological discussion. Qualitative Research, 12(6), 630-644. doi: $10.1177 / 1468794112439005$

United Nations. (1989). Convention on the Rights of the Child.

van den Hoonaard, D. K. (2014). Qualitative research in action: A Canadian primer (2nd ed.). Toronto: Oxford University Press.

Weiss, J. (2011). GL versus BT: The archaeology of biphobia and transphobia within the U.S. gay and lesbian community. Journal of Bisexuality, 11, 498-502.

Wertz, F. J. (2005). Phenomenological research methods for counseling psychology. Journal of Counseling Psychology, 52(2), 167-177. doi: 10.1037/0022-0167.5 